\title{
Molecular targeting of NOX4 for neuropathic pain after traumatic injury of the spinal cord
}

\author{
YB Im ${ }^{1}$, MK Jee ${ }^{1}$, JI Choi ${ }^{1}, \mathrm{HT}$ Cho ${ }^{1}$, OH Kwon ${ }^{1}$ and SK Kang ${ }^{\star, 1}$
}

Neuropathic pain is a well-known type of chronic pain caused by damage to the nervous system. Until recently, many researchers have primarily focused on identifying cellular or chemical sources of neuropathic pain or have approached neuropathic pain via the basis of biological study. We investigated whether both mmu-mir-23b (miR23b) and NADPH oxidase 4 (NOX4) antibody infusion can alleviate neuropathic pain by compensating for abnormally downregulated miR23b via reducing the expression of its target gene, NOX4, a reactive oxygen species (ROS) family member overexpressed in neuropathic pain. Ectopic miR23b expression effectively downregulated NOX4 and finally normalized glutamic acid decarboxylase 65/67 expression. Moreover, animals with neuropathic pain showed significantly improved paw withdrawal thresholds (PWTs) following miR23b infusion. Normalizing miR23b expression in tissue lesions, caused by neuropathic pain induction, reduced inflammatory mediators and increased several ROS scavengers. Moreover, $\gamma$-aminobutyric acid (GABA)ergic neurons coexpressed suboptimal levels of miR23b and elevated NOX4/ROS after pain induction at the cellular level. MiR23b finally protects GABAergic neurons against ROS/p38/c-Jun N-terminal kinase (JNK)-mediated apoptotic death. By evaluating the functional behavior of mice receiving pain/miR23b, normal/anti-miR23b, anti-miR23b/si-NOX4, pain/NOX4 antibody, pain/ ascorbic acid, and pain/ascorbic acid/NOX4 antibody, the positive role of miR23b and the negative role of NOX4 in neuropathic pain were confirmed. Based on this study, we conclude that miR23b has a crucial role in the amelioration of neuropathic pain in injured spinal cord by inactivating its target gene, NOX4, and protection of GABAergic neurons from cell death. We finally suggest that infusion of miR23b and NOX4 antibody may provide attractive diagnostic and therapeutic resources for effective pain modulation in neuropathic pain.

Cell Death and Disease (2012) 3, e426; doi:10.1038/cddis.2012.168; published online 15 November 2012

Subject Category: Experimental medicine

Recently, many groups have suggested a relationship between the immune system and the nervous system. Neuropathic pain is a well-known type of chronic pain caused by damage to the nervous system. Generally, it results from a variety of chronic pain conditions with various underlying pathophysiological mechanisms and origins. ${ }^{1,2}$ Among these immunoactive substances, COX2, interleukin $1 \beta$ (IL-1 $\beta)$, and tumor necrosis factor- $\alpha$ (TNF- $\alpha$ ) are globally expressed at the sites of induced pain. ${ }^{3}$ Moreover, reactive oxygen species (ROS) have an important role in regulating cell growth and death by controlling the production of superoxide and $\mathrm{H}_{2} \mathrm{O}_{2}$. Neuropathic pain also causes the release of inflammatory factors from microglia and astrocytes in the spinal cord. The NADPH oxidase family is one of the key factors for understanding pain mechanisms in pathogenic pain models because NADPH oxidase 2 (NOX2) and NADPH oxidase 4 (NOX4) have been reported to generate ROS. ${ }^{5,6}$

MicroRNAs (miRNAs), short non-coding RNAs, are endogenously expressed and directly inhibit protein translation by binding to a complementary target mRNA. Recently, the expression of miRNAs has been widely used to observe tissue-specific miRNA expression and regulatory changes in different developmental stages, cell types, and tissues. ${ }^{7-10}$ Many research groups are investigating various methods for the relief of chronic pain, including drugs and molecular factors. ${ }^{11,12}$ The first experimental reports addressing the involvement of miRNAs in the nociception clearly indicate that inflammatory muscle pain ${ }^{13}$ and peripheral nerve injury ${ }^{14}$ modify the expression profile of a number of miRNAs in trigeminal and dorsal root ganglia, respectively. ${ }^{15}$ Several groups have reported that miRNAs can control secondary injury in some animal models of disease. ${ }^{16,17}$ We found that mmu-mir-23b (miR23b) indirectly controls pain by regulating the expression of its target gene, NOX4. MiR23b has been shown to control directly NOX4 expression and affect the expression levels of inflammatory factors and ROS scavengers in animal models of pain. In this study, we explored the role of a specific miRNA, miR23b, in an in vivo animal model and in cultured neural progenitor cells (NPCs). The expression of $\gamma$-aminobutyric acid (GABA) and glutamic acid decarboxylase (GAD)67 has been shown to be reduced in animal models of pain compared with healthy animals. ${ }^{18-20}$ In

\footnotetext{
${ }^{1}$ Laboratory of Stem Cell Biology, Department of Biotechnology, College of Veterinary Medicine, Seoul National University, Seoul, Korea

${ }^{*}$ Corresponding author: SK Kang, Laboratory of Stem Cell Biology, Department of Biotechnology, College of Veterinary Medicine, Seoul National University, San 56-1 Gwanakgu Sillim-dong, Seoul 151-742, Korea. Tel: + 822880 1247; Fax: + 822880 1293; E-mail: sookang@ @nu.ac.kr

Keywords: neuropathic pain; microRNA; inflammation; NOX4; ROS

Abbreviations: NOX4, NADPH oxidase 4; GAD65/67, glutamic acid decarboxylase 65/67; ROS, reactive oxygen species; PWTs, paw withdrawal thresholds; GABA, $\gamma$-aminobutyric acid; TNF- $\alpha$, tumor necrosis factor- $\alpha$; GPX3, glutathione peroxidase 3; TXNL1, thioredoxin-like 1; DCFDA, 5-(and-6)-carboxy-2', $7^{\prime}$-dichlorodihydrofluorescein diacetate

Received 27.7.12; revised 21.9.12; accepted 05.10.12; Edited by A Finazzi-Agro'
} 
few reports describing successful medical or surgical treatments for postspinal cord injury (SCI), central neuropathic pain exists. ${ }^{20-23}$ Hypofunction of GABAergic inhibitory mechanisms and increases in calcitonin gene-related peptide in the spinal cord have both been reported after SCI. GABAmediated inhibition, acting both presynaptically and postsynaptically, exerts a tonic modulation of nociceptive neurotransmission between primary afferents and secondorder spinothalamic tract neurons. ${ }^{24-26}$

In our study, we first demonstrated that miR23b effectively reduces neuropathic pain by reducing the expression of the inflammation-promoting factor, NOX4, in an animal model, and reduction of miR23b expression produced pain symptoms. We also administered miR23b intrathecally and interfered with NOX4 expression to reduce hypersensitization of neuropathic pain induced in an animal model. Two factors acted in opposition to one another; as miR23b levels decreased, NOX4 expression increased and vice versa. Furthermore, NOX4 antibody treatment effectively reduces neuropathic pain by reducing the expression of the NOX4, effectively interfered with NOX4 expression, and significantly reduced hypersensitization of neuropathic pain in traumatic $\mathrm{SCI}$. As a result, miR23b and NOX4 antibody treatment may represent a key molecule for the protection of neural cells in neuropathic pain.

\section{Results}

MiR23b expression in an induced neuropathic pain animal model. We identified differentially expressing miRNAs and mRNA at a various time schedules $(0, S C l 24 \mathrm{~h}$, $48 \mathrm{~h}, 72 \mathrm{~h}, 1$ week) via DNA microarray and real-time reverse transcription (RT)-PCR confirmation. Among these, we selected several miRNAs that target specific neural, functional protein, which significantly upregulated compared with normal tissue. MiR23b expression levels were also confirmed by in situ hybridization and real-time RT-PCR assays at day 3 after the induction of neuropathic pain (Figure 1a). Intrathecal infusions of miR23b were used to determine the role of miR23b in neuropathic pain in this animal model. A sham-operated animal model was induced by injection of an antisense RNA to interfere with miR23b expression. We studied the role of miR23b in pathogenic pain progression using three different animal groups: a control group (untreated, healthy mouse), a pain-induced animal group (to produce sensitivity to mechanical and thermal stimuli), and a miR23b-treated group (injected with miR23b). After the injection of miR23b into the spinal cord (between T12 and L2), the expression level of miR23b in the sham-operated animal model was reduced compared with that of the neuropathic animal model (Figure 1a).

The role of miR23b in an induced neuropathic pain animal model. Our colocalization study of miR23b and specific neural cell subtypes by in situ hybridization and immunohistochemistry found that a high ratio of GABAergic neurons were colocalized with miR23b (Supplementary Figure S1). To determine the functional role of miR23b in the neuropathic pain animal model, we evaluated the functional behavior of the pain + miR23b-infused animal group, pain + scrambled (scram)RNA animal group, and healthy animal group using mechanical and heat stimulation. As a result, miR23b-infused, neuropathic pain-induced animal groups showed significant improvement in paw withdrawal thresholds (PWTs) than in the pain group without the infusion (Figure 1b).

Next, we investigated the expression level of the proteins to investigate the molecular function of miR23b in the induced pain animal model. After the intrathecal administration of miR23b into injured animals, Bax and caspase-3 expressions were significantly decreased, whereas $\mathrm{Bcl}-2$ expression was increased (Figure 1c). Previous studies have shown that factors reported to induce cell death were activated by pain. ${ }^{27,28}$ These results showed that miR23b might reduce neuropathic pain by blocking activation of proteins induced in the apoptotic cell death of nestin-positive neural precursor cells, myelin, motor neurons, and spinal cord astrocytes (Figure 1d). Immunohistochemistry also revealed that infusion of miR23b into the lesion of pain animals resulted in significantly decreased numbers of glia fibrillary acidic protein \pm astrocytes and lba1 \pm microglial cells compared to animals with neuropathic pain (Figure 1e).

MiR23b controls the pathological microenvironment of the lesion in neuropathic animals. We also evaluated the expression levels of miR23b and its major target gene, NOX4, before and after injury induction in the spinal cord. Furthermore, we examined the expression levels of miR23b, NOX2, and NOX4, and found differential expression patterns between miR23b and NOX4 (Figures $1 \mathrm{a}$ and 2d). The expression pattern of miR23b in animals with pain + scramRNA gradually decreased compared with tissue from healthy animals. In contrast, the expression levels of NOX2 and NOX4 were increased in injury animals + the scramRNA compared with healthy animals. And, NOX4 expression was significantly downregulated after miR23b infusion in the pain animal model (Figure 2b). In addition, other inflammatory factors, such as ED1, COX2, TNF- $\alpha$, and IL-1 $\beta$, showed

\footnotetext{
Figure 1 The intrathecal administration of miR23b reduces neuropathic pain in an animal model. (a) The expression level of miR23b was significantly increased after intrathecal injection of miR23b in a neuropathic pain model, as determined by RT-PCR ( ${ }^{*} P<0.01$ ) and in situ hybridization (ISH) analysis (bottom). (b) The PWT was determined using both von Frey filaments to measure the mechanical threshold and the Hargreaves method to measure noxious thermal sensitivity. After the injection of miR23b or scramRNA, mechanical and thermal hypersensitivity were attenuated for 4 weeks. ( $\left.{ }^{*} P<0.05 ;{ }^{*} P<0.01\right)$. (c) Western blot analyses were used to determine the expression levels of survival- and death-related genes. Intrathecal administration of miR23b-induced STAT3 expression and Akt activation, whereas the expression of the apoptotic cell death signals p38, JNK, Bax, and caspase-3 was reduced. (d) Furthermore, the neural markers nestin, MBP, and neurofilament 160 (NF160) were increased after intrathecal administration of miR23b. (e) The astrocyte cell marker glia fibrillary acidic protein (GFAP) and the microglia cell marker Iba1 were increased following induction of neuropathic pain, whereas injured mice receiving miR23b infusions showed decreased expression of these markers. GFAP and Iba1 were immunolabeled with anti-GFAP and anti-Iba1 antibodies, respectively
} 

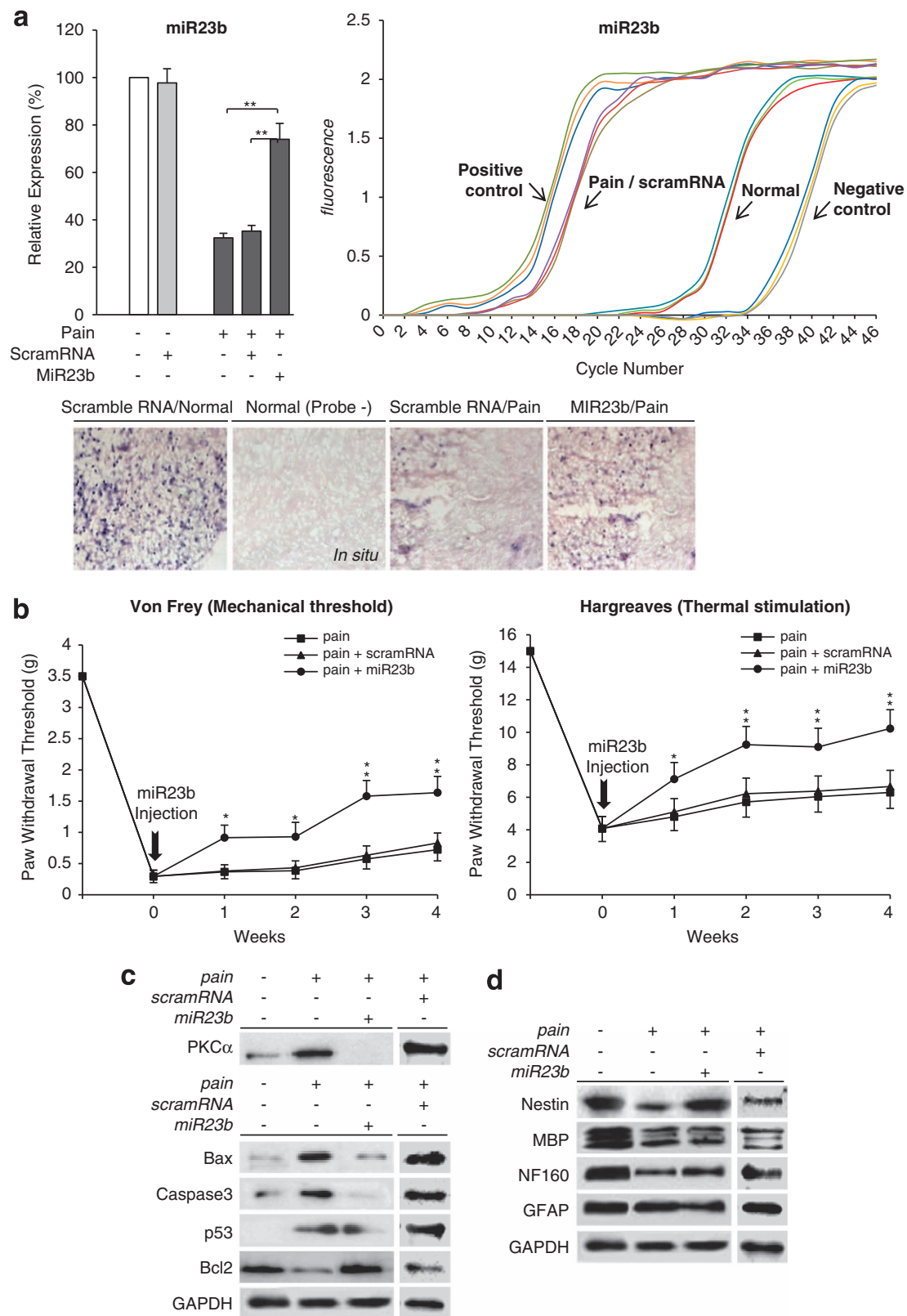

\section{d}

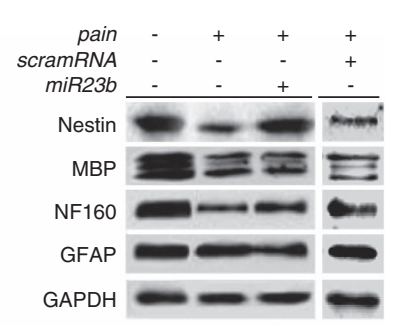

e
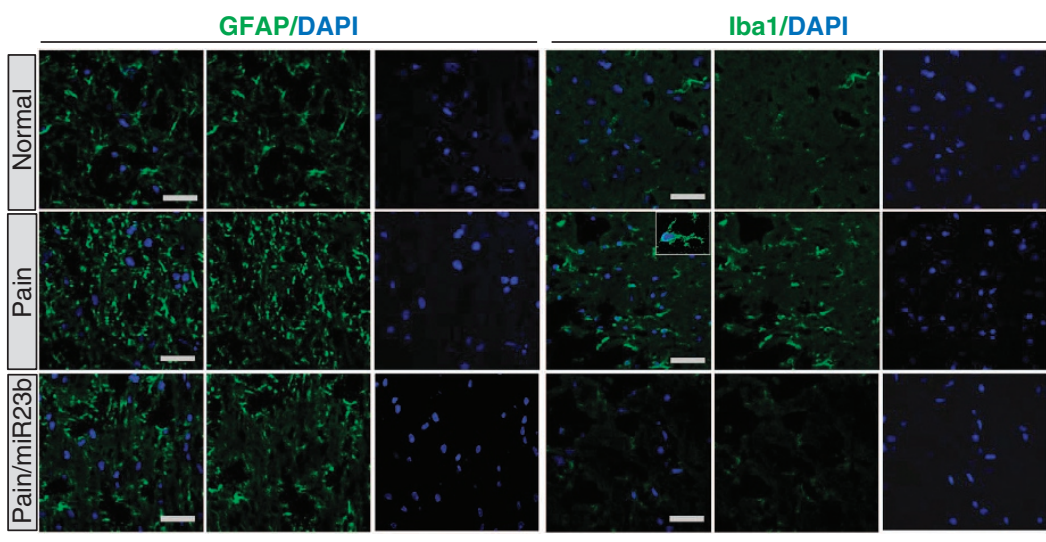
increased expression levels after traumatic SCI (Figure 2c). Simultaneously, glutathione peroxidase 3 (GPX3) and thioredoxin-like 1 (TXNL1) showed different expression levels between pain + scramRNA and pain + miR23b animals; these genes were also downregulated in mice with neuropathic pain compared to a group of healthy control mice (Figure 2d). After pain induction, the expression of GAD65 and GAD67 was significantly decreased; however, infusion of miR23b was significantly reduced GAD65 and GAD67 expressions (Figure 2e). The injured tissue produced high levels of 5-(and-6)-carboxy-2', 7'-dichlorodihydrofluorescein diacetate (DCFDA) +ROS in the lesion compared with normal tissue, and the ectopic infusion of miR23b significantly downregulated ROS generation (Supplementary Figure S2a). Next, we studied differential expression levels of GABA between pain + scramRNA animals and pain + miR23b animals by immunohistochemistry. Following the induction of pain, the expression levels of GABA were considerably decreased compared with healthy animals (Supplementary Figure S2b).

To determine the functional role of miR23b in the neuropathic pain animal model, we evaluated the functional behavior of the normal + anti-miR23b-infused animal group and healthy animal group using mechanical and heat stimulation. The normal + anti-miR23b-infused animal groups showed significant downregulation in PWTs as injured animal level (Figure 2f). Moreover, luciferase assay was performed after finding three putative binding regions of miR23b with NOX4 gene, which was located in chromosome 7 (NC_000073.5) in the mice genome (Figure 2g).

A major role for NOX4 in the pathogenesis of tissue
lesions and functional amelioration of pain in an animal
model. When NOX4 expression was increased acutely in
pain tissue, the inflammatory markers COX2, IL-1 $\beta$, and
TNF- $\alpha$ were also significantly upregulated (Table 1). And,
TNF- $\alpha$, COX2, and IL-1 $\beta$ expression levels were significantly
decreased by the injection of si-NOX4 in animals with
neuropathic pain (Table 1). The expressions of GPX1 and
GPX3 were not significantly changed after inhibition of NOX4
expression in the injured animal model, whereas expression
of the TXNL1 gene was significantly decreased along with
increased GAD65 and GAD67 expression levels in these
mice (Table 1). To define the role of miR23b expression in
the spinal cord during neuropathic pain and in healthy
animals, we reduced miR23b expression using RNAi in
healthy mice. The anti-miR23b-induced pseudo-pain mouse
model and the traumatic pain animal model showed very similar expression patterns of miR23b and NOX4, and inflammatory factors, GPX1, GPX3, and TXNL1 (Table 2). However, when we injected si-NOX4 into an anti-miR23binjected animal, the expression levels of the inflammatory factors were downregulated compared with both neuropathic pain tissue and the anti-miR23b-treated healthy animal tissue (Table 2). The expression of the ROS scavengers was affected by the expression levels of miR23b and NOX4. To determine the neuroprotective or regenerative activity on GABAergic neurons, we analyzed GAD65 and GAD67 expressions among healthy animals, animals with neuropathic pain, anti-miR23b-infused healthy animals, and anti-miR23b/ si-NOX4-infused animals. Pain and anti-miR23b-infused healthy animals showed significantly reduced GAD65 and GAD67 expressions, and GAD65 and GAD67 expressions were reduced after infusion of si-NOX4 (Table 2).

To determine the functional role of NOX4 in the neuropathic pain model, we evaluated the functional behavior of the pain + si-NOX4-infused animal group, the pain + scramRNA animal group, and healthy animals by measuring mechanical and heat sensitivity. The pain + si-NOX4-infused animal groups showed PWTs that gradually improved. In contrast, the mice with neuropathic pain did not show improved PWTs (Figures $3 a$ and b). Moreover, we evaluated the functional behavior of the anti-miR23b-infused healthy animals and antimiR23b + si-NOX4-infused healthy animals $24 \mathrm{~h}$ after surgical neuropathic pain induction, and also in healthy animals by measuring mechanical and heat sensitivity. The antimiR23b + si-NOX4-infused animals showed significantly improved PWTs compared to mice with neuropathic pain (Figure 3c).

The effect of NOX4 antibody on expression level of NOX4 on GABA neuroprotection in an induced neuropathic pain model. We studied the expression level of NOX4 in the progression of pathogenic pain using five different animal groups: a control group, a pain-induced animal group, an NOX4 antibody-treated group, an ascorbic acid-treated group, and an ascorbic acid + NOX4 antibodytreated group. The expression level of miR23b and NOX4 in the sham-operated model was reduced and was similar to that of the neuropathic animal model after an injection of phosphate-buffered saline (PBS) into the spinal cord (Figures $4 \mathrm{a}$ and b). After an intrathecal injection of normal saline, NOX4 antibody, ascorbic acid, or ascorbic acid+ NOX4 antibody, the expression level of NOX4 was analyzed for up to 7 days after injection in the induced pain model (Figure 4b). Moreover, the pain + ascorbic acid and pain +

\footnotetext{
Figure 2 The intrathecal administration of miR23b and anti-miR23b affects inflammatory factor expression, ROS production, and the expression of redox-scavenging genes. (a) Diagram showing the injection of scramRNA or miR23b with DharmaFECT. (b) RT-PCR and western blot analysis were used to determine the expression levels of ROS-generating proteins after injection of miR23b in the induced neuropathic pain model. Both NOX2 and NOX4 were significantly decreased. In contrast, the injection of antimiR23b into healthy mice induced ROS production ( $\left.{ }^{* *} P<0.01\right)$. (c) MiR23b reduced the expression of the inflammatory factors ED1, COX2, TNF- $\alpha$, and IL-1 $\beta$. However, the inflammatory factors were increased when the anti-miR23b was injected $\left({ }^{* *} P<0.01\right)$. (d) The expression of the redox-scavenger genes, especially TXNL1, was significantly increased after intrathecal administration of miR23b. In contrast, the expression levels of the redox-scavenger genes, TXNL1, were decreased after injection of anti-miR23b $\left({ }^{*} P<0.01\right)$. (e) Moreover, the expression level of GAD65/67 was also increased compared to animals with neuropathic pain, as shown by RT-PCR. However, suppression of miR23b by injection of anti-miR23b led to a dramatic decrease in GAD65/67 expression $\left({ }^{*} P<0.01\right)$. (f) The PWT was measured using von Frey to determine mechanical hypersensitivity and the Hargreaves test to measure sensitivity to noxious thermal stimulation. After the injection of anti-miR23b, hypersensitivity was significantly increased for 4 weeks, similar to the neuropathic pain model. $\left({ }^{\star} P<0.05 ;{ }^{* *} P<0.01\right)$. (g) Genomic localization and structure of $3^{\prime}$-UTR region of miR23b target sequence. Luciferase assay showed that miR23b directly bound the target gene, NOX4 $\left({ }^{\star} P<0.05\right.$; $\left.{ }^{\star *} P<0.01\right)$
} 
ascorbic acid+NOX4 antibody-treated animal groups showed significantly increased expression levels of GAD67 compared with injured animals (Figure 4c). Also, to determine the functional role of NOX4 in the neuropathic pain animal model, we evaluated the functional behavior of the pain in ascorbic acid + NOX4 antibody-treated animal a

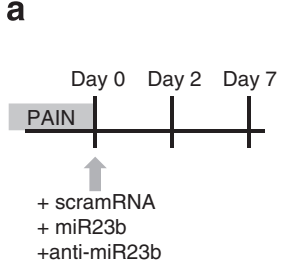

C

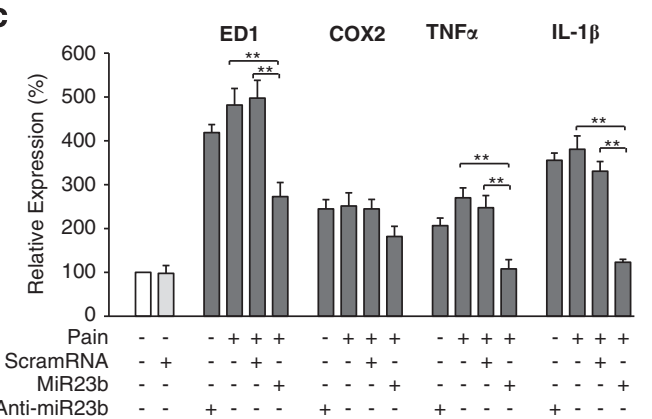

b

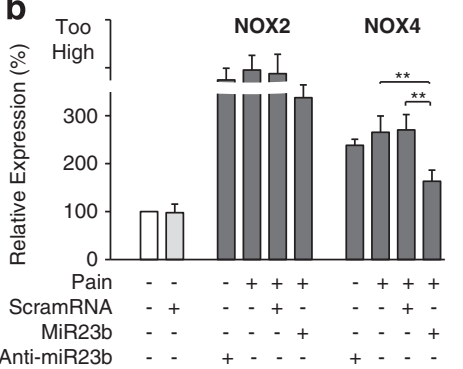

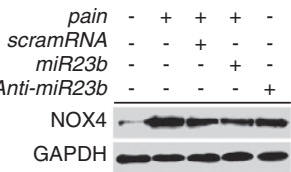

d

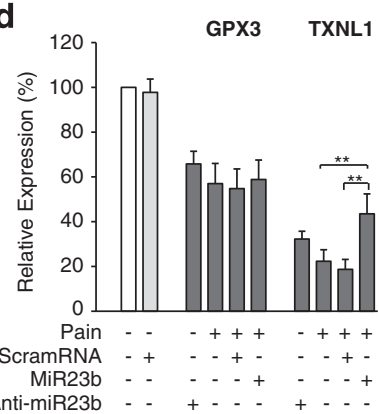

e

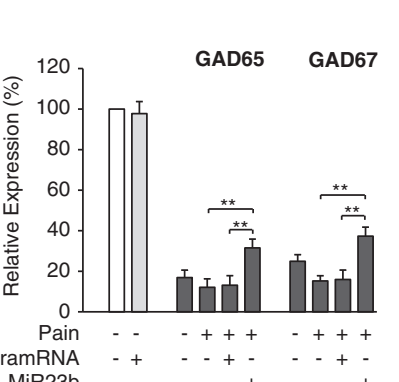

f

anti-miR23b
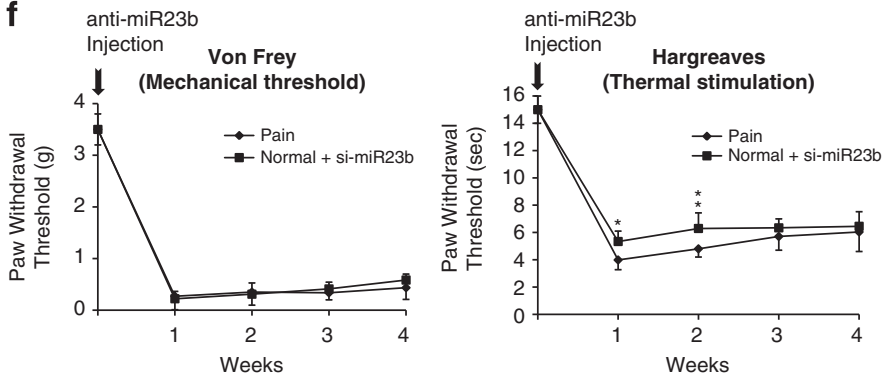

Anti-miR23b

g

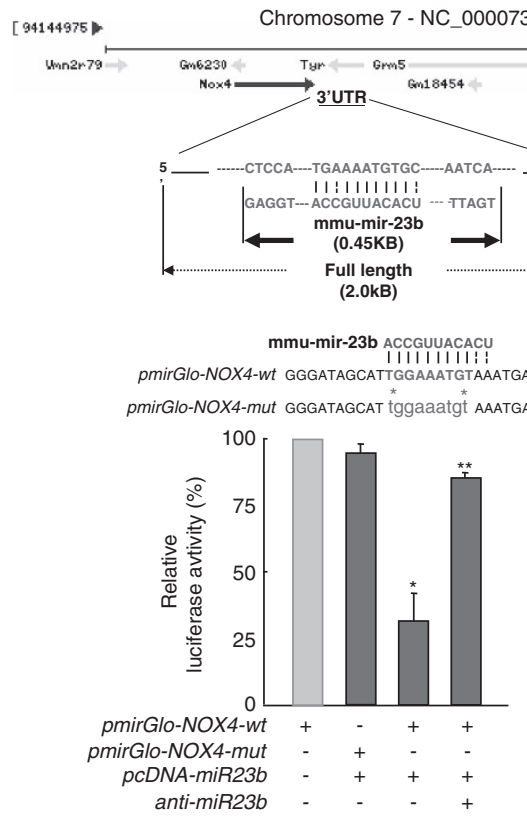


Table 1 Relative expression of functional gene cluster before and after si-NOX4 infusion in injured spinal cord tissue

\begin{tabular}{|c|c|c|c|c|c|}
\hline \multirow[t]{2}{*}{ Description } & \multirow[t]{2}{*}{ Normal } & \multicolumn{4}{|c|}{ Fold change ( $P$-value) } \\
\hline & & $\begin{array}{c}\text { ScramRNA/ } \\
\text { normal }\end{array}$ & Pain & ScramRNA/pain & Si-NOX4/pain \\
\hline \multicolumn{6}{|l|}{ Target genes } \\
\hline $\begin{array}{l}\text { miR23b } \\
\text { NOX4 }\end{array}$ & 1.00 & 1.03 & $\begin{array}{l}0.38(P<0.05) \\
3.38(P<0.01)\end{array}$ & $\begin{array}{l}0.40(P<0.05) \\
3.13(P<0.01)\end{array}$ & $\begin{array}{l}0.59(P<0.05) \\
1.48(P<0.01)\end{array}$ \\
\hline \multicolumn{6}{|c|}{ Inflammatory cytokines } \\
\hline $\begin{array}{l}\text { ED1 } \\
\text { COX2 } \\
\text { TNF- } \alpha \\
\text { IL-1 } \beta\end{array}$ & 1.00 & 1.03 & $\begin{array}{l}1.39(P<0.01) \\
4.25(P<0.01) \\
5.67(P<0.01) \\
6.55(P<0.01)\end{array}$ & $\begin{array}{l}1.43(P<0.01) \\
4.36(P<0.01) \\
5.90(P<0.01) \\
7.01(P<0.01)\end{array}$ & $\begin{array}{l}0.93(P<0.01) \\
2.52(P<0.01) \\
2.82(P<0.01) \\
4.40(P<0.01)\end{array}$ \\
\hline \multicolumn{6}{|c|}{ Redox scavengers } \\
\hline $\begin{array}{l}\text { GPX3 } \\
\text { TXNL1 }\end{array}$ & 1.00 & 1.03 & $\begin{array}{l}0.87 \text { (NS) } \\
0.61(P<0.01)\end{array}$ & $\begin{array}{l}0.87 \text { (NS) } \\
0.61(P<0.01)\end{array}$ & $\begin{array}{l}0.88(\mathrm{NS}) \\
0.94(P<0.01)\end{array}$ \\
\hline \multicolumn{6}{|c|}{ GABA enzyme } \\
\hline $\begin{array}{l}\text { GAD65 } \\
\text { GAD67 } \\
\text { GAPDH }\end{array}$ & 1.00 & 1.03 & $\begin{array}{l}0.13(P<0.01) \\
0.19(P<0.01) \\
1.00(\mathrm{NS})\end{array}$ & $\begin{array}{l}0.12(P<0.01) \\
0.19(P<0.01) \\
1.03(\mathrm{NS})\end{array}$ & $\begin{array}{l}0.27(P<0.01) \\
0.44(P<0.01) \\
1.01(\mathrm{NS})\end{array}$ \\
\hline
\end{tabular}

Table 2 Relative expression of functional gene cluster before and after anti-miR23b and anti-miR23b/si-NOX4 infusion in injured spinal cord tissue

\begin{tabular}{|c|c|c|c|c|c|}
\hline \multirow[t]{2}{*}{ Description } & \multirow[t]{2}{*}{ Normal } & \multicolumn{4}{|c|}{ Fold change ( $P$-value) } \\
\hline & & $\begin{array}{c}\text { ScramRNA } \\
\text { normal }\end{array}$ & Pain $24 \mathrm{~h}$ & $\begin{array}{l}\text { Anti-miR23b/ } \\
\text { normal } 24 \mathrm{~h}\end{array}$ & $\begin{array}{c}\text { Anti-miR23b/ } \\
\text { si-NOX4/normal } 24 \mathrm{~h}\end{array}$ \\
\hline \multicolumn{6}{|l|}{ Target genes } \\
\hline $\begin{array}{l}\text { miR 23b } \\
\text { NOX4 }\end{array}$ & 1.00 & 1.00 & $\begin{array}{l}048 \text { (NS) } \\
2.94(P<0.01)\end{array}$ & $\begin{array}{l}052(\mathrm{NS}) \\
2.88(P<0.01)\end{array}$ & $\begin{array}{l}068 \text { (NS) } \\
0.78(P<0.01)\end{array}$ \\
\hline \multicolumn{6}{|c|}{ Inflammatory cytokines } \\
\hline $\begin{array}{l}\text { ED1 } \\
\text { COX2 } \\
\text { TNF-a } \\
\text { IL-1 } \beta\end{array}$ & 1.00 & 1.00 & $\begin{array}{l}1.56(\mathrm{NS}) \\
2.92(\mathrm{NS}) \\
4.35(P<0.01) \\
7.57(P<0.01)\end{array}$ & $\begin{array}{l}1.50 \text { (NS) } \\
2.71 \text { (NS) } \\
4.45(P<0.01) \\
7.84(P<0.01)\end{array}$ & $\begin{array}{l}1.45 \text { (NS) } \\
2.55(\mathrm{NS}) \\
2.47(P<0.01) \\
5.71(P<0.01)\end{array}$ \\
\hline \multicolumn{6}{|c|}{ Redox scavengers } \\
\hline $\begin{array}{l}\text { GPX3 } \\
\text { TXNL1 }\end{array}$ & 1.00 & 1.00 & $\begin{array}{l}0.51(P<0.05) \\
0.33(P<0.01)\end{array}$ & $\begin{array}{l}0.55(P<0.05) \\
0.27(P<0.01)\end{array}$ & $\begin{array}{l}0.71(P<0.05) \\
0.54(P<0.01)\end{array}$ \\
\hline \multicolumn{6}{|c|}{ GABA enzyme } \\
\hline $\begin{array}{l}\text { GAD65 } \\
\text { GAD67 } \\
\text { GAPDH }\end{array}$ & 1.00 & 1.00 & $\begin{array}{l}012(P<0.01) \\
0.16(P<0.01) \\
0.97(\mathrm{NS})\end{array}$ & $\begin{array}{l}017(P<0.01) \\
0.19(P<0.01) \\
0.88(\mathrm{NS})\end{array}$ & $\begin{array}{l}042(P<0.01) \\
0.49(P<0.01) \\
0.93(\mathrm{NS})\end{array}$ \\
\hline
\end{tabular}

group, pain + ascorbic acid-treated animal group, pain + NOX4 antibody-treated animal group, and pain + PBStreated animal group, and also in healthy animal group after effective mechanical or heat stimulation. The NOX4 antibody-infused, injured animal groups showed significant improvement in PWTs function than the other injured, untreated animal groups, pain + ascorbic acid + NOX4 antibody-treated and pain + ascorbic acid-treated, and also in pain + PBS-treated animal groups (Figure 4d). Following NOX4 antibody treatment, caspase-3 activity was significantly decreased in pain + NOX4 antibody, pain + ascorbic acid, and pain + ascorbic acid + NOX4 antibody groups (Figure 4e). In contrast, ATP production was increased in NOX4 antibody, pain + ascorbic acid, and pain + ascorbic acid + NOX4 antibody-infused animal groups compared with the induced neuropathic pain group (Figure 4e). After that, as shown in Figure 4f, the injured tissue produced high levels of $\mathrm{DCFH}-\mathrm{DA}+$, measure of ROS, but the ectopic infusion of NOX4 antibody, ascorbic acid, or ascorbic acid+NOX4 antibody significantly downregulated the generation of ROS (Figure 4f).

NOX4 antibody treatment increases the expression of ROS scavenger genes in neuropathic animals. Following traumatic injury in the nervous system, the inflammatory factors COX2 and ED1 are produced. ${ }^{29}$ We found that IL-1 $\beta$ was significantly decreased in the NOX4 antibody-infused animals (Table 3 ). Simultaneously, well-known redox-scavenger genes, including GPX1, GPX3, and TXNL1, were significantly downregulated in mice with neuropathic pain 

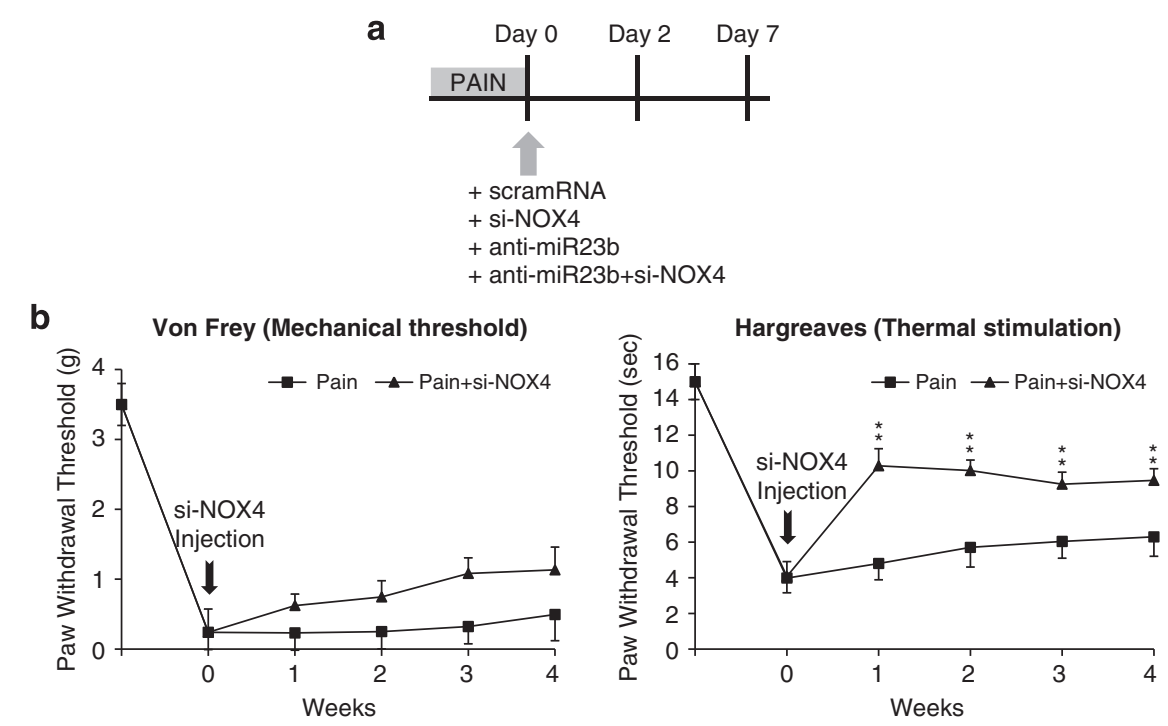

C Anti-miR23b+si-NOX4 Injection
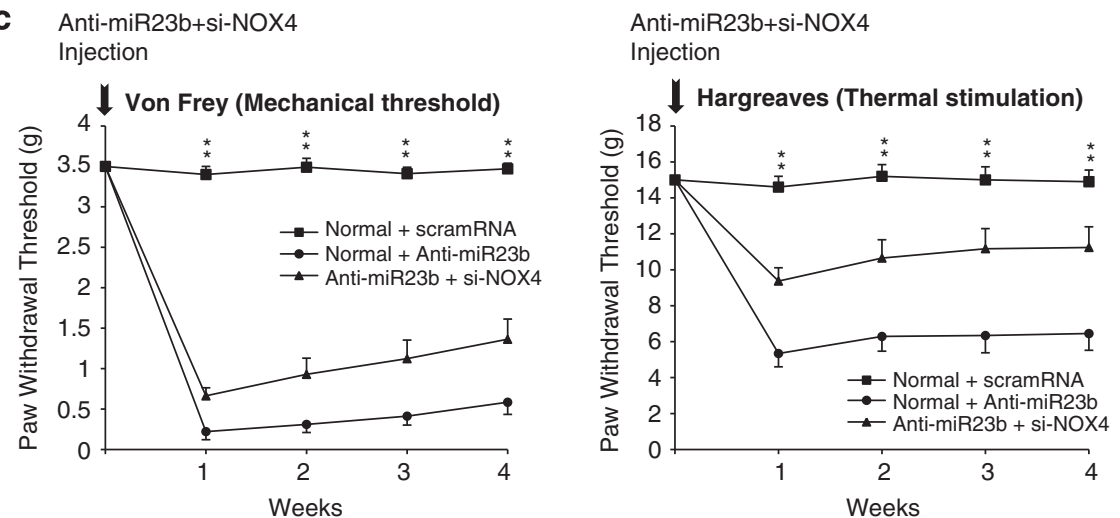

Figure 3 The intrathecal administration of si-NOX4 reduces pain in a neuropathic animal model and the therapeutic effect of si-NOX4 on anti-miR23b-induced pain. (a) Diagram showing the injection of scramRNA, si-NOX4, anti-miR23b, or anti-miR23b/si-NOX4 with DharmaFECT. (b) The PWT was measured using von Frey filaments to determine mechanical hypersensitivity and the Hargreaves method to measure thermal sensitivity. After the injection of si-NOX4, mechanical and thermal hypersensitivity were significantly decreased for 4 weeks $\left({ }^{*} P<0.05 ;{ }^{*} P<0.01\right)$. (c) The PWT was determined using von Frey filaments to measure mechanical hypersensitivity and the Hargreaves method to measure responses to noxious thermal stimulation. After the injection of si-NOX4, hypersensitivity was significantly decreased for 4 weeks $\left({ }^{*} P<0.05 ;{ }^{* *} P<0.01\right)$

compared with healthy, control mice. In contrast, the expression levels of TGF $\beta 1$ (transforming growth factor $\beta 1$ ), TGF $\beta 2$, and IL-10, modulatory inflammatory factors, were significantly increased after infusion of NOX4 antibody, ascorbic acid, or ascorbic acid+NOX4 antibody in the neuropathic pain mouse model. Collectively, infusing NOX4 antibody at the site of injury significantly reduces the expression of inflammatory factors and increases ROS scavengers in animals with neuropathic pain. Therefore, the expression level of NOX4 indirectly or directly controls inflammatory factors' expression and ROS-mediated neuronal cell death events under neuropathic pain conditions (Table 3).

As shown in Figures $5 \mathrm{a}$ and $\mathrm{b}$, the phosphorylation levels of PI3K and Akt were increased after infusion of NOX4 antibody, ascorbic acid, or ascorbic acid + NOX4 antibody (Figure 5a). In contrast, p38/JNK phosphorylation in the pain + ascorbic acid and the pain + ascorbic acid + NOX4 antibody-treated groups were significantly decreased compared with the NOX4 antibody treatment group (Figure $5 \mathrm{~b}$ ). We also investigated the effects of NOX4 antibody on neuronal death in the neuropathic pain model. After intrathecal administration of NOX4 antibody into injured, neuropathic pain animals, Erk, Bax, and caspase-3 expression levels were significantly decreased (Figure 5b). The expression of Tuj, an early neuronal progenitor or neuronal differentiation marker and myelin basic protein (MBP), was decreased after induced neuropathic pain. Western blot analysis showed that Tuj and MBP expression was significantly decreased after induction of neuropathic pain in the spinal cord (Figure $5 c$ ). In contrast, the expression of Tuj and MBP was significantly increased after infusion of NOX4 antibody, ascorbic acid, or ascorbic acid + NOX4 antibody into the lesion of neuropathic pain animals. Furthermore, we investigated that the expression levels of protein kinase $\mathrm{C} \alpha(\mathrm{PKC} \alpha)$ and protein kinase $\mathrm{C} \beta$ are located in both the peripheral and central nervous systems. ${ }^{30}$ The expression level of $\mathrm{PKC} \alpha$ was increased after injury; in contrast, it was decreased after infusion of NOX4 antibody, ascorbic acid, or ascorbic acid + NOX4 antibody in injured animal (Figure 5d). We also evaluated the expression of Iba1, a macrophage or microglia marker, and myeloperoxidase 
(MPO) via immunohistochemical analysis (Figure 5e). Both markers were significantly increased in PBS-treated animals after injury. However, the expression levels of Iba1 and MPO were significantly decreased after injection of ascorbic acid, NOX4 antibody, or ascorbic acid + NOX4 antibody (Figure 5e). Moreover, our RT-PCR and immunohistochemical results revealed that expression levels of the ROS scavenger genes, TXNL1 and GPX3, were significantly increased after injection of NOX4 antibody, ascorbic acid, or ascorbic acid + NOX4 antibody (Supplementary Figure S3). COX2 expression levels in the NOX4 antibody-treated, ascorbic acid-treated, and ascorbic acid + NOX4 antibodytreated neuropathic pain models were significantly decreased compared with PBS-treated groups.

Collectively, recent experimental results indicate that NOX4 antibody treatment after acute neuropathic pain offers the
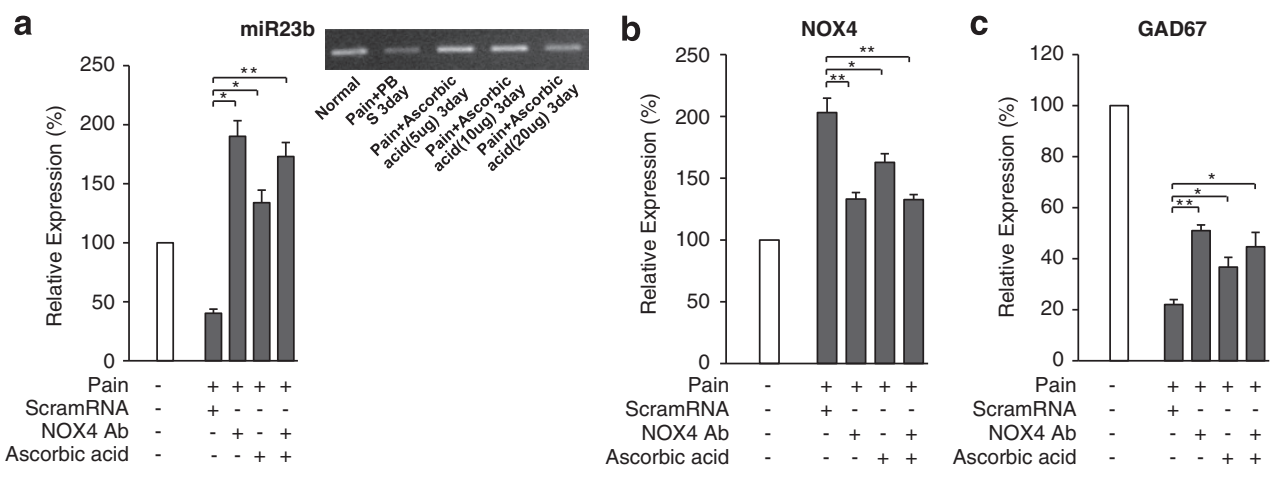

d
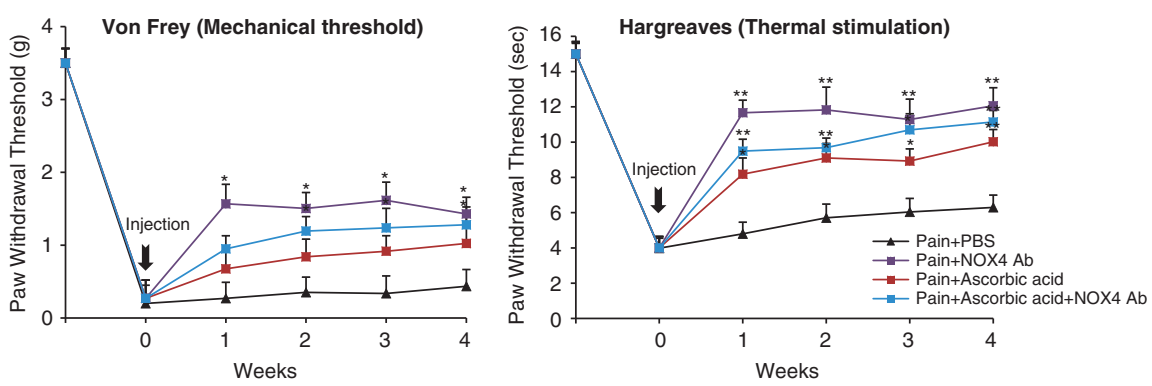

e Caspase-3 Activity
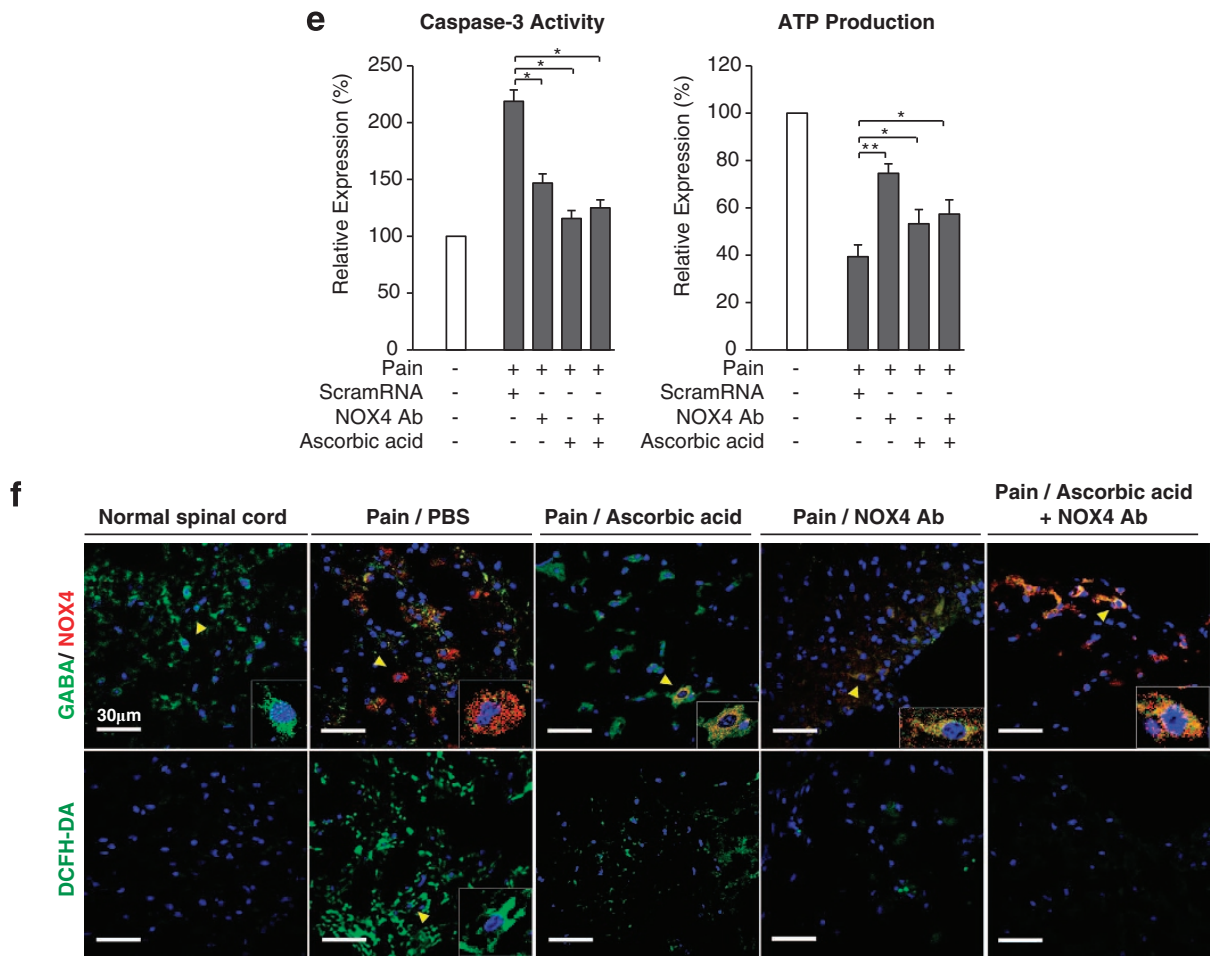
highest efficiency for protection of GABAergic neuron against pathogenic factors and ROS, including apoptotic cell death (Figure 6).

\section{Discussion}

Hypersensitivity against noxious and innocuous stimuli induces neuropathic pain that is enhanced by damage or dysfunction in the peripheral nervous system, leading to dysfunction of the central nervous system. ${ }^{31,32}$ To treat chronic pain, many researchers have investigated the use biochemical drugs, including minocycline and tetracycline, which are well absorbed, have superior tissue penetration, and are able to cross the blood-brain barrier. ${ }^{33,34}$ Minocycline is a potent inhibitor of microglial activation with no direct actions on astroglia or neurons. ${ }^{3,33}$ The anti-inflammatory and neuroprotective roles of minocycline have been studied in models of peripheral and central neuropathic pain. ${ }^{35}$ Activated microglia contributes to the maintenance of chronic pain after $\mathrm{SCl}$, focal and global ischemia, and many neurological diseases. ${ }^{34,36}$ Chemotherapeutic treatment with minocycline has been used to define the role of activated microglia in the induction and maintenance of peripheral neuropathy.,36 However, many obstacles remain in our understanding of pain pathways. There are many factors with different functions that have a role in pain in vivo. Recently, some drugs that control or suppress ERK $1 / 2$ and cyclic AMP response element-binding protein signaling have been shown to have anti-inflammatory effects. ${ }^{24}$ Activation of metabotropic glutamate receptor 7 in the spinal cord has also been shown to inhibit pain in sheep. ${ }^{37}$

Our study focused on the spinal cord miRNAs that are widely expressed in the spinal cord, and their expression levels have an important role in gene regulation in health and disease. Some research groups have studied the role of small RNAs in peripheral pain pathways. They deleted the enzyme Dicer that controls the expression of small RNA molecules, and these small RNAs were shown to affect pain. Subsequently, behavioral studies confirmed that inflammatory pain was attenuated or abolished in Dicer knockout mice. ${ }^{38}$ Another study showed that miRNAs may participate in the regulatory mechanisms of genes associated with the pathophysiology of chronic pain and the nociceptive processing following acute noxious stimulation; they found that miRNA expression in the nociceptive system shows not only temporal and spatial specificity but is also stimulus-dependent. ${ }^{15}$ These previous studies suggested that miR23b would be able to protect against severe neurodegenerative behavior in a neuropathic pain model. Our study of the function of miR23b shows that it may act in early stages of acute pain by

Table 3 Relative expression of functional gene cluster before and after NOX4 antibody (Ab), ascorbic acid, and ascorbic acid/NOX4 Ab infusion in injured spinal cord tissue

\begin{tabular}{|c|c|c|c|c|c|}
\hline \multirow[t]{2}{*}{ Description } & \multirow[t]{2}{*}{ Normal } & \multicolumn{4}{|c|}{ Fold change ( $P$-value) } \\
\hline & & ScramRNA/pain & NOX4 Ab/pain & Ascorbic acid/pain & Ascorbic acid/NOX4 Ab/pain \\
\hline \multicolumn{6}{|c|}{ Immunomodulatory factors } \\
\hline TGF $\beta 1$ & 1.00 & 0.78 & $1.88(P<0.01)$ & 1.03 (NS) & $1.38(P<0.01)$ \\
\hline TGF $\beta 2$ & & 0.52 & $1.45(P<0.01)$ & 0.73 (NS) & $1.08(P<0.05)$ \\
\hline IL-10 & & 0.46 & $0.94(P<0.05)$ & 0.72 (NS) & $0.90(P<0.05)$ \\
\hline \multicolumn{6}{|c|}{ Inflammatory cytokines } \\
\hline IL-1 $\beta$ & 1.00 & 2.86 & $1.84(P<0.05)$ & 2.48 (NS) & $1.94(P<0.05)$ \\
\hline \multicolumn{6}{|c|}{ Redox scavengers } \\
\hline GPX1 & 1.00 & 1.12 & 1.06 (NS) & 1.12 (NS) & 1.11 (NS) \\
\hline GPX3 & & 0.66 & $0.92(P<0.05)$ & $0.94(P<0.05)$ & $1.04(P<0.01)$ \\
\hline TXNL1 & & 0.24 & $1.06(P<0.05)$ & $0.85(P<0.05)$ & $1.18(P<0.05)$ \\
\hline GAPDH & & 1.03 & 0.96 (NS) & 1.04 (NS) & 1.08 (NS) \\
\hline
\end{tabular}

Figure 4 Functional amelioration efficacy of NOX4 antibody treatment after infusion. (a) The expression level of miR23b was determined by RT-PCR after injection of different dosages of ascorbic acid: 5,10 , and $20 \mu \mathrm{g}$. The expression level of miR23b was significantly increased by both the 5 and $10 \mu \mathrm{g}$ dosages of ascorbic acid. The graph shows that the expression level of miR23b was increased after injection of NOX4 antibody (Ab) and ascorbic acid + NOX4 Ab. The miR23b expression level in the NOX4 Ab-treated group was significantly increased compared with other two groups ( $\left.{ }^{\star} P<0.05 ;{ }^{\star *} P<0.01\right)$. (b) The expression level of NOX4 was significantly decreased after injection of NOX4 Ab, ascorbic acid, or ascorbic acid + NOX4 Ab ( ${ }^{*} P<0.05$; $\left.{ }^{* *} P<0.01\right)$. (c) The expression level of GAD67 was significantly increased after injection of NOX4 $\mathrm{Ab}$, ascorbic acid, or ascorbic acid + NOX4 Ab. GAD67 expression in the NOX4 Ab-treated group was significantly increased compared with other two groups $\left({ }^{\star} P<0.05\right.$; $\left.{ }^{* *} P<0.01\right)$. (d) PWTs were determined using von Frey filaments to measure hypersensitivity. At 1 week after injection of NOX4 Ab, ascorbic acid, or ascorbic acid + NOX4 $\mathrm{Ab}$, hypersensitivity was significantly decreased. PWTs were maintained for 4 weeks with similar patterns as the first week. The Hargreaves method was used to measure responses to noxious thermal stimulation. The Hargreaves test showed a significant decrease 1 week after injection that was maintained for 4 weeks. The results were similar in pattern to those of the von Frey test $\left({ }^{\star} P<0.05\right.$; $\left.{ }^{\star *} P<0.01\right)$. (e) ATP production and caspase-3 activity were determined after injection of NOX4 Ab, ascorbic acid, and ascorbic acid + NOX4 Ab. Caspase-3 activity was significantly decreased by injection of NOX4 Ab, ascorbic acid, or ascorbic acid + NOX4 Ab. ATP production was significantly increased after the injection of NOX4 Ab compared with the injured animal model. The ascorbic acid and ascorbic acid + NOX4 Ab groups showed increased ATP production. However, efficacy of ATP production was lower than the NOX4 Ab-treated group. (f) The colocalization expression levels of NOX4 (red) and GABA (green) were analyzed and compared with the pain/PBS, pain/ascorbic acid, pain/NOX4 Ab, and pain/ascorbic acid + NOX4 Ab models using confocal microscopy (arrow). The expression level of NOX4 was predominantly decreased compared to animals with neuropathic pain after injection of NOX4 Ab, ascorbic acid, or ascorbic acid + NOX4 antibody. ROS production was determined using DCFH-DA (green). ROS production was significantly increased after injury or pain/PBS, whereas it was predominantly decreased after injection of NOX4 Ab, ascorbic acid, or ascorbic acid + NOX4 Ab. Inset shows colocalization at the single-cell level 


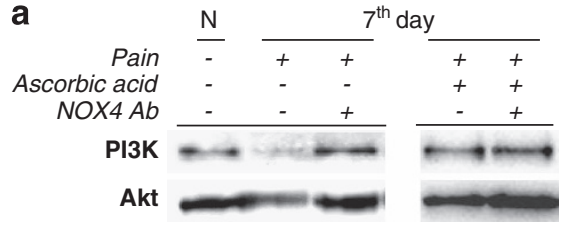

b

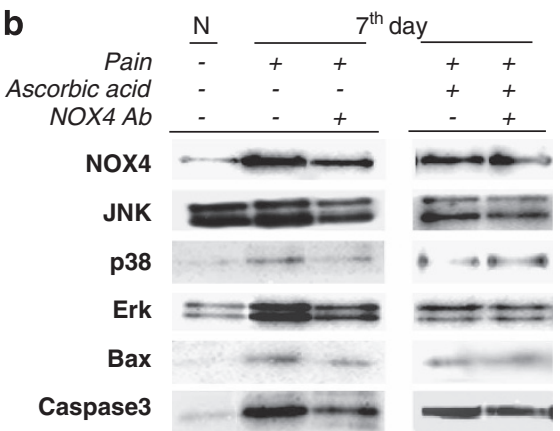

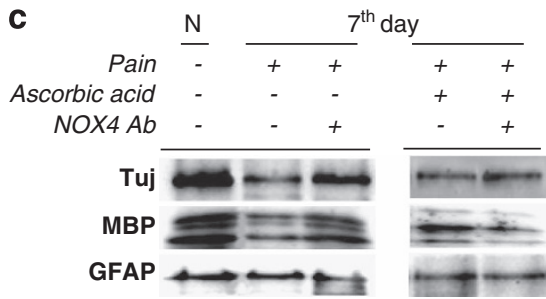

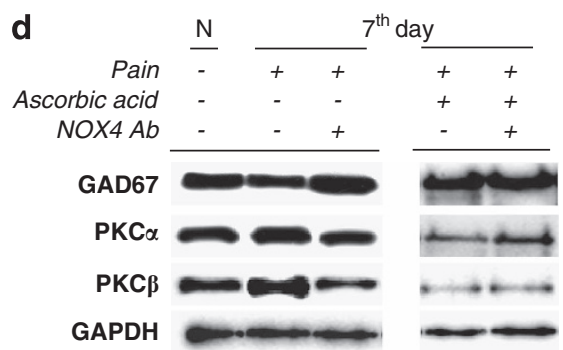

e

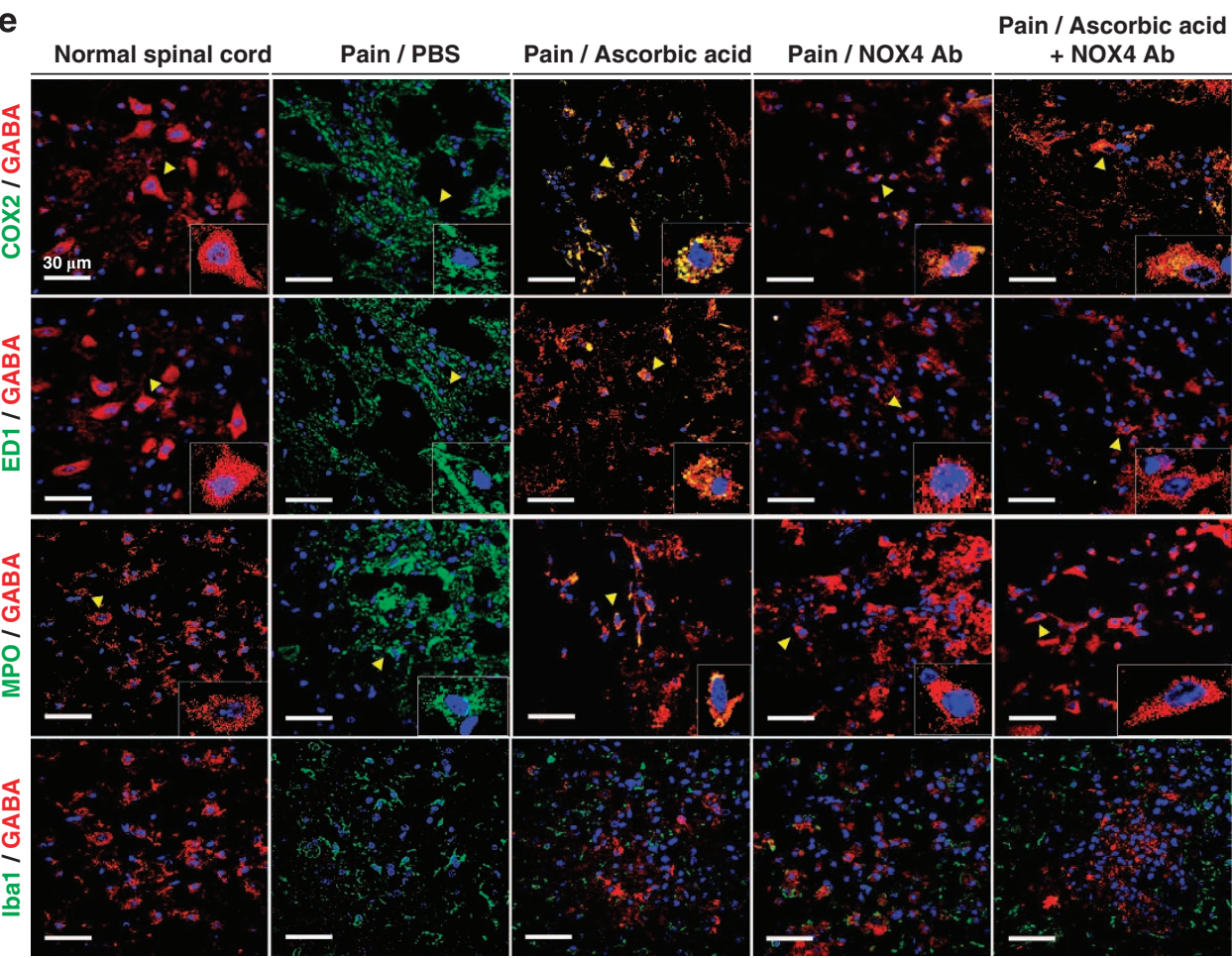

Figure 5 Intrathecal administration of NOX4 antibody (Ab), ascorbic acid, and ascorbic acid + NOX4 Ab reduced neuropathic pain into injured animals. The efficacy of the injection of NOX4 Ab, ascorbic acid, or ascorbic acid + NOX4 Ab was determined by examining various protein expression levels by western blot. Western blot analyses were used to determine the expression levels of survival- and death-related genes. (a) Intrathecal administration of NOX4 Ab, ascorbic acid, or ascorbic acid + NOX4 Ab induced PI3K expression and Akt activation, whereas (b) the expression of the apoptotic cell death signals p38, JNK, Bax, Erk, and caspase-3 was reduced. The expression level of NOX4 was reduced. (c) The neuronal markers Tuj and MBP were significantly increased after intrathecal administration of NOX4 in the NOX4 Ab-treated groups. However, glia fibrillary acidic protein (GFAP) expression was not different between pain and treated groups, NOX4 Ab, ascorbic acid, and ascorbic acid + NOX4 Ab. (d) Moreover, the expression level of GAD67 was increased compared to animals with neuropathic pain. PKC $\alpha$ and PKC $\beta$ were increased after injury. However, these factors were significantly decreased after injection of NOX4 Ab, ascorbic acid, or ascorbic acid + NOX4 Ab. (e) Intrathecal administration of NOX4 Ab, ascorbic acid, or ascorbic acid + NOX4 Ab affected expression levels of the inflammatory factor COX2, the activated microglia marker ED1, the granulocytes marker MPO, and the microglia marker Iba1. COX2, ED1, MPO, and Iba1 were immunolabeled with an anti-COX2 antibody (green), an anti-ED1 antibody (green), an anti-MPO antibody (green), and an anti-lba1 antibody (green), respectively. We showed that theose factors were colocalized with GABAergic cells via the use of an anti-GABA antibody (red). The expression levels of the factors were significantly increased in injured animals (arrow), whereas they were predominantly decreased after infusion of NOX4 Ab, ascorbic acid, or ascorbic acid + NOX 4 Ab in injured animals (arrow). Inset represents the colocalization at the single-cell level

protecting GABAergic and motor neurons. In our study, following neuropathic pain induction, miR23b expression was significantly decreased, and the expression levels of the
miR23b target gene, NOX4, and several inflammatory factors, including COX2, IL-1 $\beta$, and TNF- $\alpha$, were highly upregulated. Previously, expression levels of NOX4 in the heart were 
a

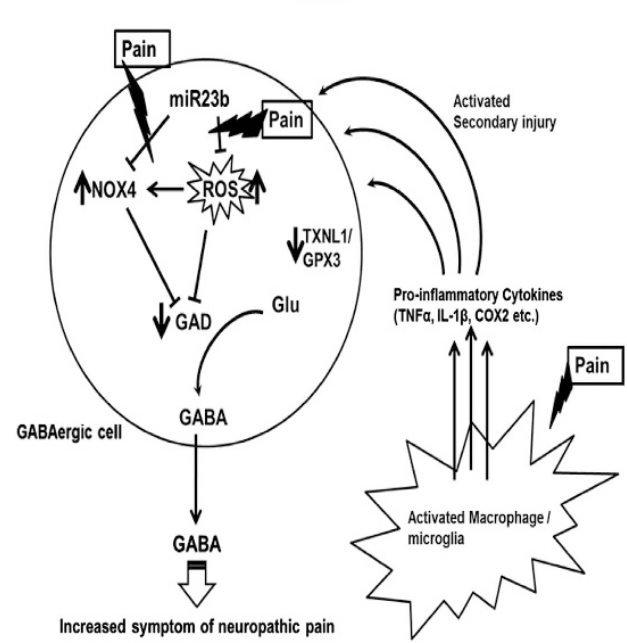

b

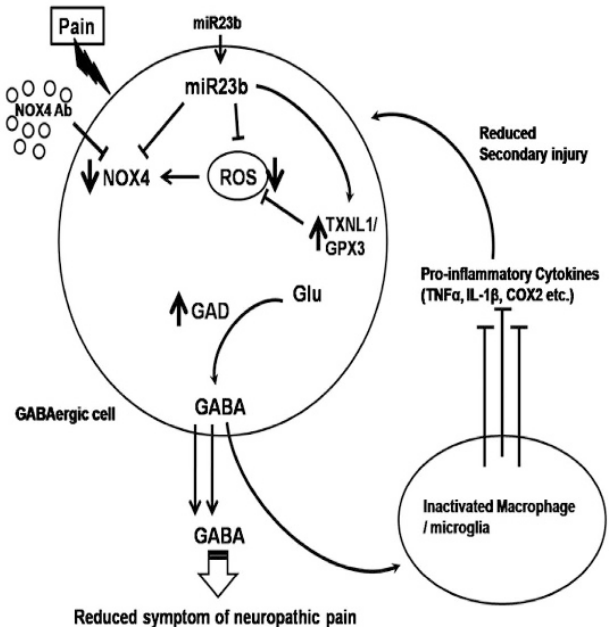

Figure 6 The functional and molecular actions of miR23b and NOX4 antibody against neuropathic pain in traumatic injured spinal cord

reported to control directly oxidative stress in the heart tissue. ${ }^{6}$ However, the role of NOX4 in the spinal cord had not been studied previously. When we injected si-NOX4 into animals with neuropathic pain, the expression levels of inflammatory factors were significantly downregulated compared with both healthy animals and animals treated with anti-miR23b. These results reveal that NOX4 is an important factor for studying pain signaling pathways, and miR23b is a key molecule for controlling NOX4 expression. In the tissue of animals with neuropathic pain, GABAergic neurons gradually degenerated in the spinal cord. We also observed downregulated expression of inflammatory factors, such as ED1, COX2, TNF- $\alpha$, and IL- $1 \beta$, in miR23b and NOX4 antibody-infused mice. Moreover, ROS generation and the expression of related genes were also affected by miR23b and NOX4 expression levels. Increasing $\mathrm{miR} 23 \mathrm{~b}$ at the site of injury reduced inflammatory factor expression and increased ROS scavenger expression levels, including GPX3 and TXNL1. Therefore, the expression pattern of miR23b and NOX4 indirectly controls inflammatory- and ROS-mediated events in an animal model of neuropathic pain.

Recently, evidence showing extensive inflammation after $\mathrm{SCl}$ has led to the clinical use of anti-inflammatory agents (such as methylprednisolone) in $\mathrm{SCl}$ patients. ${ }^{39}$ It is well accepted that post-traumatic inflammation significantly contributes to secondary injuries after SCI. Proinflammatory mediators, such as cytokines, proteases, and ROS, are believed to promote the activation of cell death executioners (for example, caspase) that are responsible for the neuronal loss and apoptosis that ultimately culminate in permanent neurological deficits. ${ }^{40,41}$ On the other hand, continual excitation may also induce the activation of signal-regulated kinases, such as ERK, p38, and JNK in glial cells. ${ }^{42,43}$ Moreover, these signaling pathways lead to the increased synthesis of multiple proinflammatory factors, including IL-1 $\beta$, TNF- $\alpha$, and NO. ${ }^{44}$ As a result of these cross-talk mechanisms between glia and neurons, the responsiveness of spinal nociceptive neurons to stimuli is believed to be further enhanced. In this way, spinal cord glia may represent novel targets for the effective treatment of pain syndromes following
SCl. ${ }^{45}$ Our study also showed increased levels of microglia and astrocytes along with increased activation of p38/JNK in spinal cord lesions after pain induction in mice. In addition, proinflammatory factor expression, including NOX4, was significantly increased after pain induction and progression. However, when we injected miR23b and NOX4 antibody into the lesion of animals with neuropathic injury, microglia, astroglia, and proinflammatory factors were significantly decreased; in contrast, GABA and GAD expression were increased. When the physiological homeostasis is destroyed by external stimuli, such as heat, ice, or chemicals, the levels of the many molecules, including GABA and GAD67, may be altered. GABA, secreted from GABAergic neurons, is one of the major factors for maintaining homeostasis and understanding pain mechanisms. GAD67, an enzyme that decarboxylates glutamate to GABA, is also an important molecule related to neuropathic pain. Both GABA and GAD67 have been shown to be downregulated following injury. ${ }^{18,29}$ In our study, the infusion of miR23b into animals with neuropathic pain reduced inflammation, decreased GABAergic neuron degeneration, and inhibited proinflammatory factor circulation into the lesion. According to the western blot and RT-PCR results, miR23b affected these changes in the expression inflammatory factors and ROS scavengers. The expression pattern at the tissue level was investigated by immunohistochemical analysis using various antibodies against GABAergic neurons, NOX4, DCFDA, COX2, and ED1. The expression and colocalization pattern of NOX4 and GABAergic neurons was also explored. Normal physiological homeostasis was disturbed by GABAergic neuron degeneration in injured spinal cords. ROS scavengers were decreased following the pathogenic pain caused by traumatic injury. In addition, immunohistochemical images revealed that ROS scavengers were overexpressed in GABAergic neurons colocalized with miR23b and NOX4 (Supplementary Figure S1). Microglial cells in injured tissue did not express NOX4. ROS scavengers have a very important role in cell survival against ROS-mediated apoptotic cell death, especially in GABAergic neuron protection and functional maintenance in 
the spinal cord. Our study showed that ROS-producing NOX4-positive cells do not express ROS scavengers, and miR23b-induced NOX4 downregulation effectively induces TXNL1, GPX3, and SEPN1 gene expression after pain induction in the spinal cord.

In this study, we suggest that miR23b has a crucial role in ameliorating neuropathic pain caused by $\mathrm{SCl}$ via NOX4 inactivation. In animals with neuropathic pain, exogenous expression of miR23b and NOX4 antibody effectively decreased pain symptoms and increased GABAergic neuron survival and recovery of GAD expression in spinal cord lesions. Exogenous miR23b expression in neuropathic lesions effectively modulated symptoms of inflammation, including microglia infiltration and inflammatory factor secretion, and reduced ROSmediated GABAergic neural cell death. Finally, we suggest that miR23b and NOX4 antibody show potential diagnostic usefulness, and molecular functional analysis of miR23b in neuropathic pain may provide attractive therapeutic tools for the treatment of pain by the regulation of NOX4 expression.

\begin{abstract}
Materials and Methods
Animal model. Adult female ICR mouse weighing $30 \mathrm{~g}$ (6-8 weeks of age) were housed in a controlled environment and provided with standard animal chow and water. Animal care was carried out in compliance with Korean regulations regarding the protection of animals used for experimental and other scientific purposes (IRB No. SNU-100629-4). A modified traumatic SCl protocol was used, as described previously. ${ }^{25}$ Under avertin anesthesia, the dorsal spinal cord of the mice was exposed using a surgical knife, and the bone from their vertebra was removed using surgical scissors and rongeurs. In brief, the spinous processes between T12 and L2 were removed with rongeurs, and a laminectomy was performed using a dental drill and rongeurs to expose the dorsal spinal cord in the anesthetized mouse. A small, longitudinal incision was made in the skin between the $\mathrm{T} 12$ and $\mathrm{L} 2$ spinous processes. For the stereotaxic injections, avertin was used at a dose of $0.2 \mathrm{ml} / 10 \mathrm{~g}$ body weight, and scramRNA, miRNA, and siRNA were injected to investigate the role of different miRNAs and proteins in neuropathic pain.
\end{abstract}

Injection of miRNA and siRNA silencing. We injected about $10 \mu \mathrm{M}$ miR23b using a microinjector with DharmaFECT. Control (vehicle) groups were also injectedwith the same concentration of scramRNA with DharmaFECT (Thermo Scientific, Rockford, IL, USA). Thereafter, the mice were raised until using experiment. The region of miR23b-injected mice was removed by cutting at a depth of $3.5 \mathrm{~mm}$ from dorsal surface of spinal cord using microscissors and blade. These collected tissue samples were used for RT-PCR and western blot. The mice were perfused by $1 \times$ PBS and $4 \%$ paraformaldehyde for immunohistochemistry. Induced pain model mice by injection of anti-miR23b were made by surgical method. Synthesized siRNA duplex was obtained from Dharmacon RNA Technologies (Thermo Scientific). Anti-miR23b was directly injected similarly to the injury site (between T12 and L2) of miR23b-injected mice without injury. Also, anti-miR23b and si-NOX4 were injected normal spinal cord and same injury region of induced pain control mice. Total injection volume was $5 \mu$, siRNA $2.5 \mu$, and DharmaFECT $2.5 \mu \mathrm{l}$. At the same time, we injected scramRNA for making sham model of each treatment mice. Sham models were also injected with the same concentration of scramRNA as treatment groups about $10 \mu \mathrm{M}$ with DharmaFECT. The siRNA provided the most efficient inhibition $(90-95 \%)$, which was utilized for the experiments. We determined each samples by time course, 1, 3, and 7 days. Injection of si-NOX4 and anti-miR23b and collection of those tissue samples followed the same method as that of the collection of miR23b tissue samples for both molecular analysis and immunohistochemistry. For inhibitor administration, DNA oligomer was directly injected into the lesion site 2 days after injury. The control (vehicle) group received the same concentration of scramRNA. The mice were then randomly assigned into three groups: 30 pain injury mice receiving miR23b inhibitor and 10 pain injury mice receiving scramRNA as controls. A total of 40 animals were utilized in these experiments.

Injection of NOX4 antibody in neuropathic pain carrying animals. We injected $10 \mu \mathrm{M}$ NOX4 antibody using a microinjector with
DharmaFECT. Control (vehicle) groups were injected with the same volume of PBS with matrigel. For tissue analysis, the lesion of NOX4 antibody-injected mice was removed by cutting to a depth of $3.5 \mathrm{~mm}$ from the dorsal surface of the spinal cord using microscissors and a blade. Collected tissue samples were used for RT-PCR, western blot, and immunohistochemical analysis. For immunohistochemistry, the mice were transcardially perfused with PBS, followed by $4 \%$ paraformaldehyde in $0.1 \mathrm{M}$ phosphate buffer. The spinal cord lesion was dissected, postfixed using same fixatives, and immersed overnight in PBS containing $30 \%$ sucrose. The spinal cord was then embedded in Tissue-Tek OCT (Sakura, Tokyo, Japan) and kept frozen at $-80^{\circ} \mathrm{C}$. Serial transverse sections (20 $\mu \mathrm{m}$ thick) were cut on a cryostat (Leica, Germany). All analysis of test or control tissue samples was performed in a randomized, observer-blinded manner.

RNA isolation and RT-PCR. Spinal cord tissue from an experimental animal that was killed was isolated by surgery. Total RNA was extracted using Trizol reagent (Invitrogen, Carlsbad, CA, USA). After isolating total RNA from previous work, RT was carried out using M-MLV reverse transcriptase (Promega, Madison, WI, USA). According to the manufacturer's protocol, we used $1 \mu \mathrm{g}$ of total RNA for RT. The PCR conditions used were as follows: initial denaturation at $94^{\circ} \mathrm{C}$ for $5 \mathrm{~min}$, followed by 35 cycles at $94^{\circ} \mathrm{C}$ for $30 \mathrm{~s}$, pertinent annealing temperature of each primer set for $30 \mathrm{~s}, 72{ }^{\circ} \mathrm{C}$ for $30 \mathrm{~s}$, and an additional cycle with extension at $72{ }^{\circ} \mathrm{C}$ for $5 \mathrm{~min}$. The normalization was carried out using GAPDH RT-PCR. The amplified products were separated by electrophoresis on $1.5 \%$ agarose gels (Invitrogen) with ethidium bromide (Amresco, Solon, OH, USA).

Western blot. Spinal cord tissues were removed by microscissors blade and were lysed with PRO-PREP (no. 17081; iNtRON Biotechnology, Sungnam, Kyungki-Do, Korea). The tissue was homogenized by homogenizer (POLYTRON PT-2100, KINEMATICA AG, Lucerne, Switzerland). After 20 min on ice, the tissue lysate was centrifuged at 12000 r.p.m. for $10 \mathrm{~min}$ and the supernatant was collected. Protein concentration was determined using the qubit fluorometer (Invitrogen). Equal amounts of sample lysates $(50 \mu \mathrm{g})$ were separated by $12 \%$ sodium dodecyl sulfate-polyacrylamide gel electrophoresis. After the gels were finished running, they were transferred to nitrocellulose transfer membrane (Whatman, Dassel, Germany). The membrane was blocked with $5 \%$ skim milk in TBST washing buffer ( $10 \mathrm{mM}$ Tris, $150 \mathrm{mM} \mathrm{NaCl}, 1 \%, \mathrm{pH} 7.4)$ with $0.1 \%$ Tween20 for $1 \mathrm{~h}$ and then incubated with primary antibodies recognizing murine $\mathrm{p}$-Ak $\mathrm{t}(1: 1000$; Cell Signaling, Billerica, MA, USA), p-Erk (1:1000; Cell Signaling), p-STAT3 (1:1000; Cell Signaling), Bax (1:200; Santa Cruz, Santa Cruz, CA, USA), caspase-3 (1:1000; Cell Signaling), p53 (1:200; Santa Cruz), JNK (1: 1000; Cell Signaling), COX2 (1:200; Santa Cruz), and NF160 (1: 200; Sigma, St Louis, MO, USA) in $5 \%$ skim milk overnight. The membrane was washed three times with TBST for $10 \mathrm{~min}$ and followed by incubation with appropriate secondary antibody for $2-4 \mathrm{~h}$, and then washed again three times with TBST. The membranes were developed using ECL as substrate. Equal loading of protein was confirmed using GAPDH (1:1000; Cell Signaling) antibody.

Immunohistochemistry. Tissues were collected by perfusion and fixed with $4 \%$ paraformaldehyde for one day at $4{ }^{\circ} \mathrm{C}$. After that, tissues were transferred onto $30 \%$ sucrose for 2 days. The tissues were molded by Frozen Section Compound (FSC 22; Leica, Buffalo Grove, IL, USA) and after 2 days transferred onto $30 \%$ sucrose. To study the expression of GABAergic neuron with inflammatory factors and ROS, spinal cords were cut in serial cross-sections ( $10 \mu \mathrm{M}$ thick) and attached on silane-coated slide glass (Micro Slides Glass; Muto Pure Chemicals, Tokyo, Japan) using microm HM525 (Thermo Scientific). The slides were dried in a chamber with ventilation system overnight. They were rinsed with $1 \times$ PBS three times for $10 \mathrm{~min}$ and incubated with a blocking solution (10\% normal goat serum (Vector Laboratories, Burlingame, CA, USA), $0.5 \%$ Triton X-100 in PBS) for $1 \mathrm{~h}$ at $4{ }^{\circ} \mathrm{C}$. The tissues were then incubated overnight at $4{ }^{\circ} \mathrm{C}$ with primary antibody, GABA (1:200; Santa Cruz), Ibal (1:300; Wako, Osaka, Japan), ED1 (1:1000; Serotec, Oxford, UK), NOX4 (1:200; Santa Cruz), DCF-DA (Invitrogen), and COX2 (1:200; Santa Cruz), diluted in blocking solution, following which the tissues were treated with the Dylight 549 Goat Anti-rabbit IgG (Thermo Scientific), Dylight 549 Anti-mouse IgG (Thermo Scientific), and Alexa Fluor 594 Anti-goat IgG secondary antibody (Invitrogen) for $10 \mathrm{~min}$. For nuclear counter-staining, Vectashield (Vector Laboratories) was diluted to $1: 20$ in blocking solution and incubated with the cells for 5 to $10 \mathrm{~min}$. Then, reacted slides were mounted and coverslipped. Images were captured with a confocal microscope (Eclipse TE200; Nikon, Tokyo, Japan). 
Luciferase assay. The oligonucleotides NOX4-Fw-wt and NOX4-Rev-wt were ligated to form a fragment containing the miR23b binding site on Ngn1 $3^{\prime}$-UTR predicted by Targetscan program (http://www.targetscan.org). The miR23b binding site with a mutated seed region was formed by annealing of NOX4-Fw-Mut and NOX4-Rev-Mut oligonucleotides. The segments were cloned downstream of the luciferase reporter gene in pmirGLO Dual-Luciferase miRNA Target Expression Vector (Promega) generating the plasmids pmiRGlo-NOX4-3'-UTRwt and pmiRGlo-NOX4-3'-UTR -Mut. The plasmid pcDNA3.1-miR23b was double digested, and the insert was subsequently cloned in vector pUHG10.3 under the control of a tetracycline-responsive promoter, generating plasmid pUHG-miR23b. This construct was sequenced to confirm the presence of correctly oriented miR23b. To determine the binding activity of miR23b on consensus sequence of target gene, NOX4, in injured spinal cord tissue, NPC cells were seeded in six-well plates until $70 \%$ confluence and pUHG-miR23b was transfected using Lipofectamine LTX and Plus Reagent, referring to the manufacturer's protocol (Invitrogen). After transfection of each plasmid, cells were incubated with DMEM containing $10 \% \mathrm{FBS}$. Cells were harvested $24-48 \mathrm{~h}$ later for dual luciferase assays (Bright Glo; Promega) to determine the promoter activity of the test plasmid. Firefly luciferase expression from the test plasmid and Renilla luciferase expression from phRL-SV40 in a single sample were measured sequentially in a luminometer according to the Dual-Luciferase Reporter System protocol (Bright Glo; Promega).

In situ hybridization. In situ hybridization of miR23b was performed on the injured or normal spinal cord tissues. Oligonucleotide probes were synthesized (Bioneer, Daejeon, Korea). Tissue slides were air dried and prepared for $15 \mathrm{~min}$ in saline citrate $(\mathrm{pH} 7.0)$, containing $0.1 \mathrm{mg} / \mathrm{ml}$ proteinase K (Sigma Aldrich), at room temperature. Sections were washed two times in $1 \times$ saline sodium citrate (SSC) for $5 \mathrm{~min}$. Labeled oligonucleotides were diluted $(30 \mathrm{pM})$ in hybridization buffer containing $50 \%$ de-ionized formamide, $4 \times \mathrm{SSC}$, and $1 \mathrm{mM}$ sodium pyrophosphate, covered with parafilm and incubated in a humid chamber overnight at $42{ }^{\circ} \mathrm{C}$. Next day after incubation, the slides were rinsed for $10 \mathrm{~min}$ in $1 \times \mathrm{SSC}$ at room temperature, $20 \mathrm{~min}$ in $1 \times \mathrm{SSC}$ at $60^{\circ} \mathrm{C}$ incubator, $5 \mathrm{~min}$ in distilled water at room temperature, dehydrated in 70,95 and $100 \%$ isopropanol, and finally air dried. Finally slides were evaluated using a Leica fluorescence microscope (Leica Microsystems, Exon, PA, USA)

Caspase-3 activity. Tissues were collected from the neuropathic pain lesion by surgery. To assess caspase-3 activity, tissue lysate was rotated using rotator a $4{ }^{\circ} \mathrm{C}$ for $2 \mathrm{~h}$. After that, the tissue lysate was centrifuged at 12000 r.p.m. for $10 \mathrm{~min}$. Supernatant moved to a new microtube. Protein concentration was determined using the qubit fluorometer (Invitrogen). In total, $10 \mu \mathrm{g}$ of protein was isolated from injured spinal cord tissues in a total volume of $50 \mu$ and was mixed with $50 \mu$ l of equilibrated Caspase-Glo 3 reagents (Promega). After $2 \mathrm{~h}$ incubation at room temperature, luminescence was measured using a TD 20/20 Luminometer (Turner Designs, Sunnyvale, CA, USA). Experimental values were corrected for background, and the fold or relative increase in activity was calculated based on the activity measured in untreated cells. All reactions were performed in triplicate.

ATP production. The amount of protein was determined using the Protein Assay Kit (Bio-Rad, Hercules, CA, USA) following the manufacturer's instructions. Cells were resuspended in buffer containing $150 \mathrm{mmol} / / \mathrm{KCl}, 25 \mathrm{mmol} / \mathrm{l} \mathrm{Tris}-\mathrm{HCl}$ (pH 7.6), $2 \mathrm{mmol} / / \mathrm{EDTA}(\mathrm{pH} 7.4), 10 \mathrm{mmol} / / \mathrm{KPO}_{4}(\mathrm{pH} 7.4), 0.1 \mathrm{mmol} / \mathrm{I} \mathrm{MgCl} 2$ and $0.1 \%(\mathrm{w} / \mathrm{v})$ bovine serum albumin at a concentration of $1 \mathrm{mg}$ protein per $\mathrm{ml}$ of buffer. ATP synthesis was initiated by the addition of $250 \mu$ lof the cell suspension to $750 \mu$ l of substrate buffer $(10 \mathrm{mmol} / / \mathrm{malate}, 10 \mathrm{mmol} / /$ pyruvate, $1 \mathrm{mmo} / / \mathrm{ADP}$, $40 \mu \mathrm{g} / \mathrm{ml}$ digitonin, and $0.15 \mathrm{mmol} / \mathrm{l}$ adenosine pentaphosphate). Cells were incubated at $37^{\circ} \mathrm{C}$ for $10 \mathrm{~min}$. At 0 and $10 \mathrm{~min}, 50 \mu \mathrm{l}$ aliquots of the reaction mixture were withdrawn, quenched in $450 \mu \mathrm{l}$ of boiling $100 \mathrm{mmol} / \mathrm{l} \mathrm{Tris}-\mathrm{HCl}$, $4 \mathrm{mmol} / / \mathrm{EDTA}$ (pH 7.75) for $2 \mathrm{~min}$, and further diluted $1 / 10$ in the quenching buffer. The quantity of ATP was measured in a luminometer (Berthold; Detection Systems, Pforzheim, Germany) with the ATP Bioluminescence Assay Kit (Roche Diagnostics, Basel, Switzerland) following the manufacturer's instructions.

\section{Behavior test}

von Frey. The presence of mechanical allodynia was determined by measuring PWTs to mechanical indentation of the plantar surface of each hindpaw using von Frey filaments. The filaments are capable of exerting forces of 10, 20, 40,60, 80, or $120 \mathrm{mN}$, but have the same tip diameter of $0.1 \mathrm{~mm}$. These filaments were applied to three designated loci distributed over the plantar surface of the foot.
During each test, the mouse was placed in a transparent plastic box over a wire mesh floor. The cage was elevated so that stimulation could be applied to each hind foot from beneath the mouse. Each filament was applied alternately to each foot and each locus. The duration of each stimulus was $1 \mathrm{~s}$, and the interstimulus interval was approximately 5 to $10 \mathrm{~s}$. The incidence of foot withdrawal was expressed as a percentage of the five applications of each stimulus as a function of force. The PWT was defined as the force corresponding to a $50 \%$ withdrawal, as determined by linear interpolation. To reduce the effects of pre-existing differences among individuals in mechanical responsiveness, the withdrawal thresholds were also normalized by subtracting each value on the treated (ipsilateral) side from the corresponding value on the contralateral side.

Hargreaves. After surgery, the animals were inspected every 1 or 2 days and at weekly intervals thereafter until 8 weeks. For general observation, the mice were placed on a table and notes were made on the animal's gait and the posture of each hind paw. The presence of thermal hyperalgesia was determined by measuring the foot withdrawal latency in response to heat stimulation. Each mouse was placed in a box on the glass floor of the Hargreaves apparatus. The temperature of the glass floor was measured and maintained at $27^{\circ} \mathrm{C}$. A heat source (IITC Model 390 Analgesia Meter, Series 8; Life Science Products, Frederick, CA, USA) was positioned beneath a portion of the hind paw that was flushed against the glass, and a thermal stimulus was delivered to that site. When the hind paw moved, the stimulus was removed, and the time was recorded; at a maximum cutoff value of $20 \mathrm{~s}$, the stimulus automatically shut off. The intensity of the heat stimulus was maintained at a constant value throughout all experiments. The elicited paw withdrawal latency was approximately $10-15 \mathrm{~s}$ in the control mice. Thermal stimuli were delivered 3-5 times to each hind paw at 5- to 6-min intervals. At least three blind observers scored all behavior tests and were positioned across from each other to observe both sides of the mice.

Statistic analysis. Data were reported as the mean \pm S.E.M. from five or more independent experiments. Statistically significant differences in functional recovery between groups were calculated by repeated measures of the analysis of variance (ANOVA) test. ANOVA was performed followed by Student's $t$-test to determine statistically significant differences.

\section{Conflict of Interest}

The authors declare no conflict of interest.

Acknowledgements. This work was supported by the National Research Foundation of Korea (NRF) grant funded by the Korea Government (MEST, 20100020265).

1. Vallejo R, Tilley DM, Vogel L, Benyamin R. The role of glia and the immune system in the development and maintenance of neuropathic pain. Pain Pract 2010; 10: 167-184.

2. Andrade P, Visser-Vandewalle V, Philippens M, Daemen MA, Steinbusch HW, Buurman WA et al. Tumor necrosis factor- $\alpha$ levels correlate with postoperative pain severity in lumbar disc hernia patients: opposite clinical effects between tumor necrosis factor receptor 1 and 2. Pain 2011; 152: 2645-2652.

3. Ledeboer A, Sloane EM, Milligan ED, Frank MG, Mahony JH, Maier SF et al. Minocycline attenuates mechanical allodynia and proinflammatory cytokine expression in rat models of pain facilitation. Pain 2005; 115: 71-83.

4. Fan S, Li L, Chen S, Yu Y, Qi M, Tashiro S et al. Silibinin induced-autophagic and apoptotic death is associated with ROS and RNS increase in HeLa cells. Free Radic Res 2011; 45: 1307-1324

5. Kim D, You B, Jo EK, Han SK, Simon MI, Lee SJ. NADPH oxidase 2-derived reactive oxygen species in spinal cord microglia contribute to peripheral nerve injury-induced neuropathic pain. Proc Natl Acad Sci USA 2010; 107: 14851-14856.

6. Ago T, Kuroda J, Pain J, Fu C, Li H, Sadoshima J. Upregulation of Nox4 by hypertrophic stimuli promotes apoptosis and mitochondrial dysfunction in cardiac myocytes. Circ Res 2010; 106: 1253-1264.

7. Markou A, Liang $Y$, Lianidou E. Prognostic, therapeutic and diagnostic potential of microRNAs in non-small cell lung cancer. Clin Chem Lab Med 2011; 49: 1591-1603.

8. Mukhopadhyay P, Brock G, Appana S, Webb C, Greene RM, Pisano MM. MicroRNA gene expression signatures in the developing neural tube. Birth Defects Res A 2011; 91: 744-762. 
9. Schneider M, Andersen DC, Silahtaroglu A, Lyngbaek S, Kauppinen S, Hansenm JL et al. Cell-specific detection of microRNA expression during cardiomyogenesis by combined in situ hybridization and immunohistochemistry. J Mol Histol 2011; 42: 289-299.

10. Smirnova L, Grafe A, Seiler A, Schumacher S, Nitsch R, Wulczyn FG. Regulation of miRNA expression during neural cell specification. Eur J Neurosci 2005; 21: 1469-1477.

11. Austin PJ, Moalem-Taylor G. The neuro-immune balance in neuropathic pain: involvement of inflammatory immune cells, immune-like glial cells and cytokines. J Neuroimmunol 2010; 229: 26-50.

12. Carlton SM, Hargett GL. Colocalization of metabotropic glutamate receptors in rat dorsal root ganglion cells. J Comp Neurol 2007; 501: 780-789.

13. Bai G, Ambalavanar R, Wei D, Dessem D. Downregulation of selective microRNAs in trigeminal ganglion neurons following inflammatory muscle pain. Mol Pain 2007; 3: 15-18.

14. Aldrich BT, Frakes EP, Kasuya J, Hammond DL, Kitamoto T. Changes in expression of sensory organ-specific microRNAs in rat dorsal root ganglia in association with mechanical hypersensitivity induced by spinal nerve ligation. Neuroscience 2009; 164: 711-723.

15. Kusuda R, Cadetti F, Ravanelli M, Sousa TA, Zanon S, De Lucca FL et al. Differential expression of microRNAs in mouse pain models. Mol Pain 2011; 7: 17.

16. Zhao Y, Ransom JF, Li A, Vedantham V, von Drehle M, Muth AN et al. Dysregulation of cardiogenesis, cardiac conduction, and cell cycle in mice lacking miRNA-1-2. Cell 2007; 129: 303-317.

17. van Rooij E, Sutherland LB, Liu N, Williams AH, McAnally J, Gerard RD et al. A signature pattern of stress-responsive microRNAs that can evoke cardiac hypertrophy and heart failure. Proc Natl Acad Sci USA 2006; 103: 18255-18260.

18. Gwak YS, Hulsebosch CE. GABA and central neuropathic pain following spinal cord injury. Neuropharmacology 2011; 60: 799-808.

19. Siddall PJ, Loeser JD. Pain following spinal cord injury. Spinal Cord 2001; 39: 63-73.

20. Hama A, Sagen J. Activation of spinal and supraspinal cannabinoid-1 receptors leads to antinociception in a rat model of neuropathic spinal cord injury pain. Brain Res 2011; 1412: 44-54.

21. Kumru H, Soler D, Vidal J, Tormos JM, Pascual-Leone A, Valls-Sole J. Evoked potentials and quantitative thermal testing in spinal cord injury patients with chronic neuropathic pain Clin Neurophysiol 2012; 123: 598-604.

22. Boroujerdi A, Zeng J, Sharp K, Kim D, Steward O, Luo ZD. Calcium channel alpha-2-delta1 protein upregulation in dorsal spinal cord mediates spinal cord injury-induced neuropathic pain states. Pain 2011; 152: 649-655.

23. Hama A, Sagen J. Antinociceptive effect of riluzole in rats with neuropathic spinal cord injury pain. J Neurotrauma 2011; 28: 127-134.

24. Joo JD, Choi JW, In JH, Jung HS, Lee JA, Kim YS et al. Lidocaine suppresses the increased extracellular signal-regulated kinase/cyclic AMP response element-binding protein pathway and pro-inflammatory cytokines in a neuropathic pain model of rats. Eur Soc Anaesthesiol 2011; 28: 106-111.

25. Kang SK, Shin MJ, Jung JS, Kim YG, Kim CH. Autologous adipose tissue-derived stromal cells for treatment of spinal cord injury. Stem Cells Dev 2006; 15: 583-594.

26. Arienti C, Daccò S, Piccolo I, Redaelli T. Osteopathic manipulative treatment is effective on pain control associated to spinal cord injury. Spinal Cord 2011; 49: 515-519.

27. Nakagawa T, Kaneko S. Spinal astrocytes as therapeutic targets for pathological pain. J Phamacol Sci 2010; 114: 347-353.

28. Voscopoulos C, Lema M. When does acute pain become chronic? Br J Anaesth 2010; 105: i69-i85.

29. Yowtak J, Lee KY, Kim HY, Wang J, Kim HK, Chung K et al. Reactive oxygen species contribute to neuropathic pain by reducing spinal GABA release. Pain 2011; 152: 844-852.
30. Velázquez KT, Mohammad H, Sweitzer SM. Protein kinase C in pain: involvement of multiple isoforms. Phamacol Res 2007; 55: 578-589.

31. Merskey H. Clarifying definition of neuropathic pain. Pain 2002; 96: 408-409.

32. Ossipov MH, Lai Jr J, Malan TP, Porreca F. Spinal and supraspinal mechanisms of neuropathic pain. Ann NY Acad Sci 2000; 909: 12-24.

33. Kielian T, Esen N, Liu S, Phulwani NK, Syed MM, Phillips N et al. Minocycliine modulates neuroinflammation independently of its antimicrobial activity in Staphylococcus aureusinduced brain abscess. Am J Pathol 2007; 171: 1199-1214.

34. Yrjänheikki J, Tikka T, Keinänen R, Goldsteins G, Chan PH, Koistinaho J. A tetracycline derivative, minocycline, reduces inflammation and protects against focal cerebral ischemia with a wide therapeutic window. Proc Natl Acad Sci USA 1999; 96: 13496-13500.

35. Raghavendra V, Tanga F, DeLeo JA. Inhibition of microglial activation attenuates the development but not existing hypersensitivity in a rat model of neuropathy. $J$ Pharmacol Exp Ther 2004; 306: 624-630.

36. Sapadin AN, Fleischmajer R. Tetracyclines: nonantibiotic properties and their clinical implications. J Am Acad Dermatol 2006; 54: 258-265.

37. Dolan S, Gunn MD, Crossan C, Nolan AM. Activation of metabotropic glutamate receptor 7 in spinal cord inhibits pain and hyperalgesia in a novel formalin model in sheep. Behav Pharmacol 2011; 22: 582-588.

38. Zhao J, Lee MC, Momin A, Cendan CM, Shepherd ST, Baker MD et al. Small RNAs control sodium channel expression, nociceptor excitability, and pain thresholds. J Neurosci 2010; 30: $10860-10871$.

39. Bracken MB. Treatment of acute spinal cord injury with methylprednisolone: results of a multicenter, randomized clinical trial. J Neurotrauma 1991; 8: S47-S50.

40. Hurlbert RJ. Methylprednisolone for acute spinal cord injury: an inappropriate standard of care. J Neurosurg 2000; 93: 1-7.

41. Shin MS, Chung BS, Kim YS. Effect of cyclosporin a in a rat spinal cord injury model. J Korean Neurosurg Soc 1998; 27: 1361-1369.

42. Colburn RW, Rickman AJ, DeLeo JA. The effect of site and type of nerve injury on spinal glial activation and neuropathic pain behavior. Exp Neurol 1999; 157: 289-304.

43. Hauben E, Gothilf A, Cohen A, Butovsky O, Nevo U, Smurnov I et al. Vaccination with dendritic cells pulsed with peptides of myelin basic protein promotes functional recovery from spinal cord injury. J Neurosci 2003; 23: 8808-8819.

44. Yune TY, Lee JY, Jung GY, Kim SJ, Jiang MH, Kim YC et al. Minocycline alleviates death of oligodendrocytes by inhibiting pro-nerve growth factor production in microglia after spinal cord injury. J Neurosci 2007; 27: 7751-7761.

45. Jiang F, Liu T, Cheng M, Pang XY, Bai ZT, Zhou JJ et al. Spinal astrocyte and microglial activation contributes to rat pain-related behaviors induced by the venom of scorpion buthus martensi karch. Eur J Pharmacol 2009; 623: 52-64.

(c)

Cell Death and Disease is an open-access journal published by Nature Publishing Group. This work is licensed under the Creative Commons Attribution-NonCommercial-No Derivative Works 3.0 Unported License. To view a copy of this license, visit http://creativecommons.org/licenses/by-nc-nd/3.0/

Supplementary Information accompanies the paper on Cell Death and Disease website (http://www.nature.com/cddis) 